\title{
Design of co-crystals/salts of some Nitrogenous bases and some derivatives of thiophene carboxylic acids through a combination of hydrogen and halogen bonds
}

\author{
Samson Jegan Jennifer and Packianathan Thomas Muthiah*
}

\begin{abstract}
Background: The utility of N-heterocyclic bases to obtain molecular complexes with carboxylic acids is well studied. Depending on the solid state interaction between the N-heterocyclic base and a carboxylic acid a variety of neutral or ionic synthons are observed. Meanwhile, pyridines and pyrimidines have been frequently chosen in the area of crystal engineering for their multipurpose functionality. HT (hetero trimers) and LHT (linear heterotetramers) are the well known synthons that are formed in the presence of pyrimidines and carboxylic acids.

Results: Fourteen crystals involving various substituted thiophene carboxylic acid derivatives and nitrogenous bases were prepared and characterized by using single crystal X-ray diffraction. The 14 crystals can further be divided into two groups [1a-7a], [8b-14b] based on the nature of the nitrogenous base. Carboxylic acid to pyridine proton transfer has occurred in 3 compounds of each group. In addition to the commonly occurring hydrogen bond based pyridine/ carboxylic acid and pyrimidine/carboxylic acid synthons which is the reason for assembly of primary motifs, various other interactions like $\mathrm{Cl} \ldots \mathrm{Cl}, \mathrm{Cl} \ldots \mathrm{O}, \mathrm{C}-\mathrm{H} \ldots \mathrm{Cl}, \mathrm{C}-\mathrm{H} \ldots \mathrm{S}$ add additional support in organizing these supermolecules into extended architectures. It is also interesting to note that in all the compounds $\pi-\pi$ stacking occurs between the pyrimidine-pyrimidine or pyridine-pyridine or acid-acid moieties rather than acid-pyrimidine/pyridine.

Conclusions: In all the compounds (1a-14b) either neutral O-H... N $\mathrm{N}_{\text {pyridyl/pyrimidine }}$ or charge-assisted $\mathrm{N}_{\text {pyridinium }}-\mathrm{H} \ldots \mathrm{O}_{\text {carboxylate }}$ hydrogen bonds are present. The HT (hetero trimers) and LHT (linear heterotetramers) are dominant in the crystal structures of the adducts containing N-heterocyclic bases with two proton acceptors (1a-7a). Similar type supramolecular ladders are observed in 5TPC44BIPY (8b), TPC44BIPY (9b), TPC44TMBP (11b). Among the seven compounds [8b-14b] the extended ligands are linear in all except for the TMBP (10b, 11b, 12b). The structure of each compound depends on the dihedral angle between the carboxyl group and the nitrogenous base. All these compounds indicate three main synthons that regularly occur, namely linear heterodimer (HD), heterotrimer $(\mathrm{HT})$ and heterotetramer (LHT).
\end{abstract}

Keywords: 5-chlorothiophen-2-carboxylic acid, Halogen bonding, Bipyridine, Pyrimidine, Salts, Cocrystal

\section{Background}

The utilization of intermolecular interactions for directed self assembly in order to understand their strength, directionality as well as distance is perhaps the main goal of supramolecular chemistry and crystal engineering [1-6]. The identification of various commonly occurring synthons between two functional groups not only adds to knowledge

* Correspondence: tommtrichy@yahoo.co.in

School of Chemistry, Tiruchirappalli 620024, Tamil Nadu, India but also simplifies the design and prediction of such supramolecular assemblies [7-9]. These interactions involve electrostatic, hydrogen bonding, Van der Waals and pi-pi stacking interactions. The perfect example that emphasizes the importance of hydrogen bonding is provided by Mother Nature in the form of complementary base pairing of the double helix of DNA [10,11]. Recently halogen bonding is a paradigm that complements the role of hydrogen bonding and its importance in formation of crystal structures has also
(D) Chemistry Central 
been emphasized [12-14]. Also in recent years, the advances in this field have enabled the design and synthesis of molecules of pharmaceutical importance with improved physicochemical properties [15-18]. The utility of N-heterocyclic bases to obtain molecular complexes with carboxylic acids is well studied [19-23]. Depending on the solid state interaction between the $\mathrm{N}$-heterocyclic base and a carboxylic acid a variety of neural or ionic synthons are observed.

Meanwhile, pyridines and pyrimidines have been frequently chosen in the area of crystal engineering for their multipurpose functionality. HT (hetero trimers) and LHT (linear heterotetramers) are the well known synthons that are formed in the presence of pyrimidines and carboxylic acids (Scheme 1). Especially the bipyridyl species with the robust hydrogen bonding sites and high molecular symmetry make it a versatile building block in building crystalline materials [23-26]. For the sake of further investigation, it is worthwhile to analyze and compare complex structures based on these pyridines and pyrimidines with rigid building blocks such as TPC, 5-TPC and TDC (TPC $=$ Thiophene 2-carboxylic acid, 5-TPC $=5$-Chloro thiophene 2- carboxylic acid, TDC-Thiophene dicarboxylic acid). 5-TPC has been an interesting ligand to us due to its hydrogen bonding ability as well as formation of interesting $\mathrm{Cl} . . . \mathrm{Cl}$ and $\mathrm{C}-\mathrm{H}$...Cl halogen bonding interactions $[23,27-30]$. Beyond this, the aim of this work is to compare the differences that occur during the interchange of pyridines/pyrimidines and to list out the commonly occurring motifs. In our current investigation, the expected carboxylpyridyl heterosynthon $\left[\mathrm{O}-\mathrm{H} . . . \mathrm{N}_{\text {pyridyl }}\right]$ with graph set notation $\mathrm{R}_{2}{ }^{2}(7)$ is completely absent (Scheme 2). Instead of the $\mathrm{R}_{2}{ }^{2}(7)$ heterosynthon a single point synthon is observed (Scheme 2). This $\mathrm{R}_{2}{ }^{2}(7)$ hetero synthon is the most commonly occuring and the reliable recognition pattern between the carboxyl and pyridyl groups [6,31,32].

\section{Results and discussion}

Crystallographic data for the compounds (1a-7a) and $(\mathbf{8 b}-\mathbf{1 4 b})$ are summarized in (Tables 1 and 2) respectively. The hydrogen bonding parameters for the compounds $(\mathbf{1 a - 7 a )}$ and (8b-14b) are listed in (Tables 3 and 4) respectively. ORTEP views of compounds (1a-7a) and (8b-14b) are shown in (Figures 1 and 2) respectively. Detailed structural description of all the co-crystals and salts are given below in succession. The details of the co-formers are given in (Scheme 3).

\section{Crystal structure description of 5TPCAMPY (1a)}

5TPCAMPY crystallizes in $\mathrm{P} 2{ }_{1} / \mathrm{c}$ monoclinic space group where the asymmetric unit consists of one molecule of AMPY and two crystallographically independent molecules of 5TPC. The desired primary $\mathrm{N}-\mathrm{H}$...O and $\mathrm{O}-\mathrm{H} . .$. $\mathrm{N}$ hydrogen bonding interactions between the two carboxylic groups of two 5TPC and the AMPY molecule result in the formation of a heterotrimer (HT) (Scheme 1). The commonly occurring $\mathrm{R}_{2}{ }^{2}(8)$ synthon by hydrogen bonds in the presence of pyrimidine/carboxylic acid interaction is the primary motif. The carboxylic acid moieties are coplanar with respect to the thiophene ring of the 5TPC resulting in a trimer. Adjacent trimers produced from these two strong hydrogen bonds are connected via two symmetry related hydrogen bonds involving $\mathrm{H}$ on the thiophene ring and $\mathrm{O}$ on the carboxylic acid, (Figure 3a). This results in the formation of hexameric supermolecule with the formation of $\mathrm{R}_{2}{ }^{2}(10)$ synthon (Figure 3a). All these six molecules lie in the same plane they are connected to similar typed six molecules lying on the same plane by a pair of soft C-H...O hydrogen bonds in between the methyl group of pyrimidine and carboxylic acid group of 5-TPC (Figure 3b). There are $\mathrm{Cl}-\pi$ interactions observed between chlorine of thiophene ring and the thiophene ring of the adjacent hexameric supermolecule. These interactions are observed in between $\mathrm{Cl} 1 \mathrm{~A} \rightarrow \mathrm{Cg} 3$ [symmetry code: $-1+\mathrm{X}, 1 / 2-\mathrm{Y},-1 / 2+\mathrm{Z}$ ] and $\mathrm{Cl} 2 \mathrm{~A} \rightarrow \mathrm{Cg} 2$ [symmetry code: $1+\mathrm{X}, 1 / 2-\mathrm{Y}, 1 / 2+\mathrm{Z}$ ] (where $\mathrm{Cg} 2=\mathrm{S} 1 \mathrm{~A}$, $\mathrm{C} 2 \mathrm{~A} \rightarrow \mathrm{C} 5 \mathrm{~A} ; \mathrm{Cg} 3=\mathrm{S} 2 \mathrm{~A}, \mathrm{C} 7 \mathrm{~A} \rightarrow \mathrm{C} 10 \mathrm{~A})$.

\section{Crystal structure description of TPCAMPY (2a)}

The TPCAMPY crystallizes in the same $\mathrm{P} 2{ }_{1} / \mathrm{c}$ monoclinic space group as that of 5TPCAMPY, but the expected

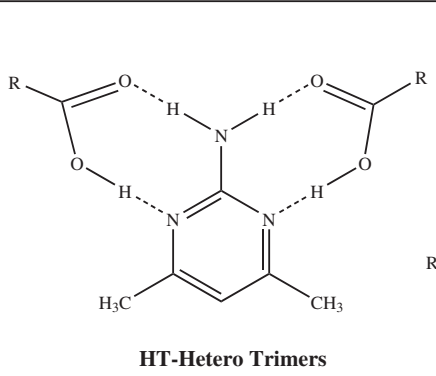

(a)

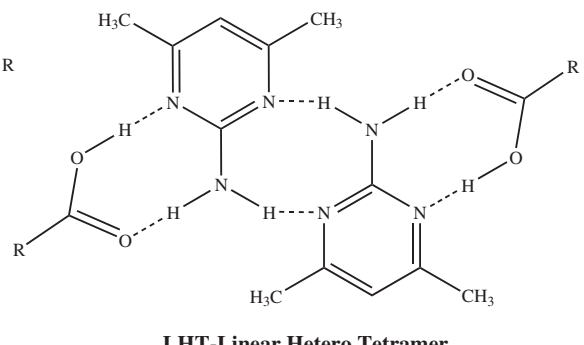

(b)

Scheme 1 Supramolecular heterosynthons that can be formed between carboxylic acids heterocyclic nitrogen of the AMPY: (a) hetero trimer (HT) (Synthon type-I) (b) linear hetero tetramer (LHT) (Synthon type-II). 


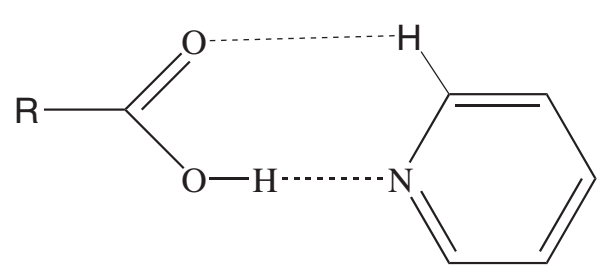

(a)

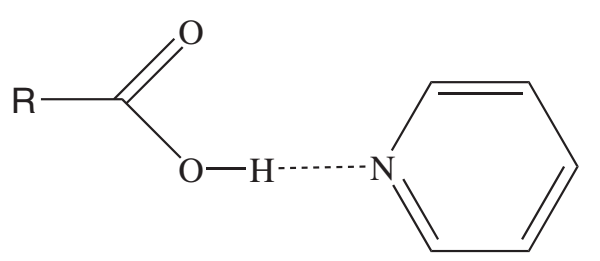

(c)

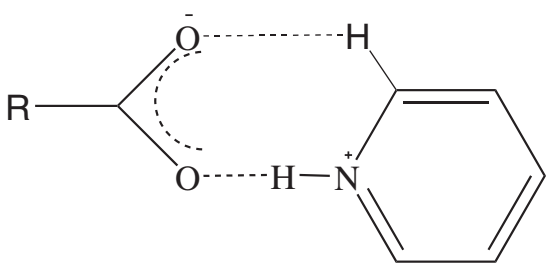

(b)

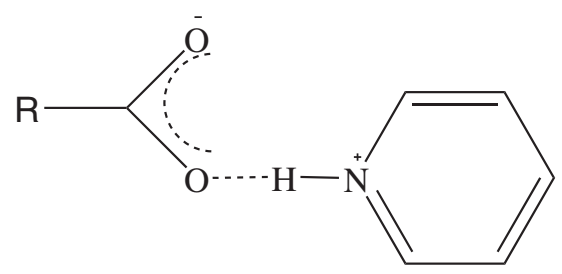

(d)

HD-Hetero Dimers

Scheme 2 Supramolecular hetero dimers that can be formed between carboxylic acids/carboxylate and heterocyclic nitrogen: (a) carboxylic acid-aromatic nitrogen with $\mathrm{R}_{\mathbf{2}}{ }^{2}(7)$ synthon (Synthon type-III)(b) pyridinium-carboxylate with $\mathrm{R}_{2}{ }^{2}(7)$ synthon (Synthon type-IV) (c) carboxylic acid-aromatic nitrogen with single point heterosynthon (Synthon type-V)and (d) pyridinium-carboxylate with single point heterosynthon (Synthon type-VI).

neutral molecules were not observed, instead the asymmetric unit consists of a pyrimidinium cation $\left(\mathrm{AMPY}^{+}\right)$and a thiophene2-carboxylate anion $\left(\mathrm{TPC}^{-}\right)$. In (1a) the primary motif is composed of 5TPC and AMPY which is connected through a couple of strong $(\mathrm{O}-\mathrm{H}$... N and $\mathrm{N}-\mathrm{H}$... $\mathrm{O}$ hydrogen bonds), whereas in (2a), it is made up of charge-assisted hydrogen bond interactions between the carboxylate and the amino-pyrimidinium moieties through $\mathrm{N}-\mathrm{H} \cdots \mathrm{O}^{-}$and $\mathrm{N}-\mathrm{H}^{+} \ldots \mathrm{O}^{-}$hydrogen bonds. This leads to the formation of $\mathrm{R}_{2}{ }^{2}(8)$ ring motif between

Table 1 Crystallographic data for structures $1 \mathrm{a}-7 \mathrm{a}$

\begin{tabular}{|c|c|c|c|c|c|c|c|}
\hline Sample code & 5TPCAMPY (1a) & TPCAMPY (2a) & TDCAMPY (3a) & 5TPCCYT (4a) & 5TPCBA (5a) & 5TPC2NPY (6a) & 5TPCACR (7a) \\
\hline Empirical Formula & $\begin{array}{c}\mathrm{C}_{6} \mathrm{H}_{9} \mathrm{~N}_{3 \prime} \\
2\left(\mathrm{C}_{5} \mathrm{H}_{3} \mathrm{Cl} \mathrm{S}\right)\end{array}$ & $\begin{array}{l}\mathrm{C}_{6} \mathrm{H}_{10} \mathrm{~N}_{3 \prime} \\
\mathrm{C}_{5} \mathrm{H}_{3} \mathrm{O}_{2} \mathrm{~S}\end{array}$ & $\mathrm{C}_{6} \mathrm{H}_{9} \mathrm{~N}_{3}, \mathrm{C}_{6} \mathrm{H}_{4} \mathrm{O}_{4} \mathrm{~S}$ & $\begin{array}{c}\mathrm{C}_{4} \mathrm{H}_{6} \mathrm{~N}_{3} \mathrm{O}, \mathrm{C}_{4} \mathrm{H}_{5} \\
\mathrm{~N}_{3} \mathrm{O}, \mathrm{C}_{5} \mathrm{H}_{2} \mathrm{Cl} \mathrm{O}_{2} \mathrm{~S}\end{array}$ & $\begin{array}{c}\mathrm{C}_{12} \mathrm{H}_{11} \mathrm{~N}_{5}, \mathrm{C}_{5} \\
\mathrm{H}_{3} \mathrm{Cl} \mathrm{O}_{2} \mathrm{~S}\end{array}$ & $\begin{array}{c}\mathrm{C}_{5} \mathrm{H}_{7} \mathrm{~N}_{2}, \mathrm{C}_{5} \\
\mathrm{H}_{2} \mathrm{Cl} \mathrm{O}_{2} \mathrm{~S}\end{array}$ & $\begin{array}{c}\mathrm{C}_{13} \mathrm{H}_{9} \mathrm{~N}, \mathrm{C}_{5} \\
\mathrm{H}_{3} \mathrm{Cl} \mathrm{O}_{2} \mathrm{~S}\end{array}$ \\
\hline Formula weight & 448.35 & 251.31 & 295.32 & 384.81 & 387.85 & 256.71 & 341.81 \\
\hline Temp, K & 296 & 296 & 296 & 296 & 296 & 296 & 296 \\
\hline$\lambda(\AA)$ & 0.71073 & 0.71073 & 0.71073 & 0.71073 & 0.71073 & 0.71073 & 0.71073 \\
\hline Crystal system & Monoclinic & Monoclinic & Monoclinic & Triclinic & Triclinic & Monoclinic & Triclinic \\
\hline Space group & $P 2_{1} / C$ & $P 2_{1} / C$ & $\mathrm{P} 2_{1} / \mathrm{C}$ & $P-1$ & $P-1$ & $\mathrm{P} 2_{1} / \mathrm{C}$ & $P-1$ \\
\hline $\mathrm{a}(\AA)$ & $7.9724(3)$ & $6.5830(2)$ & $7.6474(3)$ & $7.2399(1)$ & $4.9941(3)$ & $8.4777(8)$ & $7.6417(1$ \\
\hline$b(\AA)$ & 11.4924(3) & $25.0842(7)$ & 23.8704(7) & $7.4140(1)$ & $11.3127(7)$ & $12.4062(12)$ & $8.8984(2)$ \\
\hline$c(\AA)$ & $21.6804(7)$ & $9.6092(3)$ & $14.7634(5)$ & $17.4125(3)$ & 16.3754(9) & 11.9771(10) & $12.1882(2)$ \\
\hline$a\left({ }^{\circ}\right)$ & 90 & 90 & 90 & $89.751(1)$ & $106.595(4)$ & 90 & $73.569(1)$ \\
\hline$\beta\left({ }^{\circ}\right)$ & $96.742(2)$ & $128.170(2)$ & $92.372(2)$ & $88.462(1)$ & $92.393(4)$ & $111.541(6)$ & $87.200(1)$ \\
\hline$Y\left({ }^{\circ}\right)$ & 90 & 90 & 90 & $61.449(1)$ & $100.126(4)$ & 90 & $86.598(1)$ \\
\hline$V\left(\AA^{3}\right)$ & 1972.67(11) & $1247.48(7)$ & 2692.70(16) & $820.65(2)$ & $868.66(9)$ & 1171.72(19) & $793.09(2)$ \\
\hline Z & 4 & 4 & 8 & 2 & 2 & 4 & 2 \\
\hline Final $R_{1}$ index $[I>2 \sigma(I)]$ & 0.0390 & 0.0757 & 0.0451 & 0.0444 & 0.0585 & 0.0398 & 0.0401 \\
\hline$w R_{2}$ (all data) & 0.0891 & 0.2970 & 0.1570 & 0.1331 & 0.1345 & 0.1242 & 0.1070 \\
\hline $\begin{array}{l}\text { Largest difference in } \\
\text { peak and hole }\left(e \AA^{-3}\right)\end{array}$ & $-0.19,0.16$ & $-0.57,0.90$ & $-0.23,0.27$ & $-0.54,0.70$ & $-0.23,0.46$ & $-0.49,0.82$ & $-0.21,0.18$ \\
\hline
\end{tabular}


Table 2 Crystallographic data for Structures 8b-14b

\begin{tabular}{|c|c|c|c|c|c|c|c|}
\hline Sample code & $\begin{array}{l}\text { 5TPC44BIPY } \\
(8 \mathrm{~b})\end{array}$ & $\begin{array}{l}\text { TPC44BIPY } \\
\text { (9b) }\end{array}$ & $\begin{array}{c}\text { 5TPC44TMBP } \\
(10 \mathrm{~b})\end{array}$ & $\begin{array}{l}\text { TPC44TMBP } \\
(11 \mathrm{~b})\end{array}$ & $\begin{array}{l}\text { TDC44TMBP } \\
(12 \mathrm{~b})\end{array}$ & $\begin{array}{c}\text { 5TPC44BIPZ } \\
(13 \mathrm{~b})\end{array}$ & $\begin{array}{c}\text { 5TPC44PYNO } \\
(14 b)\end{array}$ \\
\hline Empirical Formula & $\begin{array}{c}\mathrm{C}_{10} \mathrm{H}_{8} \mathrm{~N}_{2,2} \\
\left(\mathrm{C}_{5} \mathrm{H}_{3} \mathrm{Cl} \mathrm{O}_{2} \mathrm{~S}\right)\end{array}$ & $\begin{array}{l}\mathrm{C}_{10} \mathrm{H}_{8} \mathrm{~N}_{2,}, \\
\left(\mathrm{C}_{5} \mathrm{H}_{4} \mathrm{O}_{2} \mathrm{~S}\right)\end{array}$ & $\begin{array}{l}\mathrm{C}_{13} \mathrm{H}_{14} \mathrm{~N}_{2}, 2 \\
\left(\mathrm{C}_{5} \mathrm{H}_{3} \mathrm{Cl} \mathrm{O}_{2} \mathrm{~S}\right)\end{array}$ & $\begin{array}{l}\mathrm{C}_{13} \mathrm{H}_{15} \mathrm{~N}_{2}, \mathrm{C}_{5} \mathrm{H}_{4} \\
\mathrm{O}_{2} \mathrm{~S}, \mathrm{C}_{5} \mathrm{H}_{3} \mathrm{O}_{2} \mathrm{~S}\end{array}$ & $\begin{array}{l}\mathrm{C}_{13} \mathrm{H}_{16} \mathrm{~N}_{2}, \mathrm{C}_{6} \mathrm{H}_{4} \\
\mathrm{O}_{4} \mathrm{~S}, \mathrm{C}_{6} \mathrm{H}_{2} \mathrm{O}_{4} \mathrm{~S}\end{array}$ & $\begin{array}{c}\mathrm{C}_{10} \mathrm{H}_{22} \mathrm{~N}_{21} \\
2\left(\mathrm{C}_{5} \mathrm{H}_{3} \mathrm{Cl} \mathrm{O} \mathrm{O}_{2} \mathrm{~S}\right), \\
2\left(\mathrm{C}_{5} \mathrm{H}_{2} \mathrm{Cl} \mathrm{O}_{2} \mathrm{~S}\right)\end{array}$ & $\begin{array}{c}\mathrm{C}_{10} \mathrm{H}_{8} \mathrm{~N}_{2} \mathrm{O}_{2 \prime} \\
2\left(\mathrm{C}_{5} \mathrm{H}_{3} \mathrm{Cl} \mathrm{O}_{2} \mathrm{~S}\right)\end{array}$ \\
\hline Formula weight & 481.37 & 412.49 & 523.45 & 454.57 & 542.59 & 818.66 & 513.37 \\
\hline Temp, K & 296 & 296 & 296 & 296 & 296 & 296 & 296 \\
\hline$\lambda(\AA)$ & 0.71073 & 0.71073 & 0.71073 & 0.71073 & 0.71073 & 0.71073 & 0.71073 \\
\hline Crystal system & Monoclinic & Orthorhombic & Monoclinic & Orthorhombic & Monoclinic & Triclinic & Monoclinic \\
\hline Space group & $\mathrm{P} 2_{1} / \mathrm{C}$ & $\mathrm{Pbcn}$ & $\mathrm{C} 2$ & $\mathrm{Pna}_{1}$ & $\mathrm{P} 2_{1} / \mathrm{m}$ & $P-1$ & $\mathrm{P} 2_{1} / \mathrm{C}$ \\
\hline $\mathrm{a}(\AA)$ & $3.8843(1)$ & 26.1893(5) & 24.9390(4) & $16.8789(4)$ & $6.9798(1)$ & 8.3133(1) & $6.8923(5)$ \\
\hline$b(\AA)$ & $28.0949(5)$ & $7.4673(2)$ & 4.7213(1) & $5.9661(1)$ & $18.8881(4)$ & $9.5054(1)$ & 13.0669(8) \\
\hline$c(\AA)$ & $9.6835(2)$ & $10.0668(2)$ & $10.4626(2)$ & $22.7337(5)$ & $9.8801(2)$ & $11.9923(2)$ & $11.9438(7)$ \\
\hline$a\left({ }^{\circ}\right)$ & 90 & 90 & 90 & 90 & 90 & $90.270(1)$ & 90 \\
\hline$\beta\left({ }^{\circ}\right)$ & 105.086(1) & 90 & $93.980(2)$ & 90 & $110.087(1)$ & $105.535(1)$ & $95.316(5)$ \\
\hline$Y\left({ }^{\circ}\right)$ & 90 & 90 & 90 & 90 & 90 & $97.778(1)$ & 90 \\
\hline$V\left(\AA^{3}\right)$ & $1020.33(4)$ & 1968.70(8) & $1228.94(4)$ & 2289.31(8) & 1223.31(4) & $903.79(2)$ & $1071.04(12)$ \\
\hline Z & 2 & 4 & 2 & 4 & 2 & 1 & 2 \\
\hline Final R1 index $[\mid>2 \sigma(l)]$ & 0.0385 & 0.0400 & 0.0371 & 0.0608 & 0.0335 & 0.0400 & 0.0452 \\
\hline $\mathrm{wR}_{2}$ (all data) & 0.1040 & 0.1258 & 0.1061 & 0.1904 & 0.0909 & 0.1519 & 0.1336 \\
\hline $\begin{array}{l}\text { Largest difference in } \\
\left.\text { peak and hole (e } \AA^{-3}\right)\end{array}$ & $-0.18,0.33$ & $-0.27,0.17$ & $-0.21,0.22$ & $-0.42,0.66$ & $-0.22,0.20$ & $-0.27,0.34$ & $-0.33,0.27$ \\
\hline
\end{tabular}

them (Figure 4). The secondary synthons involving the $\mathrm{N}-\mathrm{H} \cdots \mathrm{N}$ hydrogen bonds are responsible for the formation of the linear heterotetramer (LHT) (Scheme 1). The adjacent heterotetramers next to the carboxylate groups (on both sides) do not lie in the same plane and they are connected by a C-H...O hydrogen bonding interactions between hydrogen of thiophene ring of a LHT and carboxylate oxygen of another LHT (Figure 4). This gives rise to a chain of hydrogen bonds. The pyrimidine ring of a LHT present in a plane, exhibits stacking interactions with another pyrimidine ring lying in parallel planes.

\section{Crystal structure description of TDCAMPY (3a)}

As both (1a) and (2a), 3a also crystallizes in the same $\mathrm{P} 2{ }_{1} / \mathrm{c}$ monoclinic space group. The asymmetric unit consists of two crystallographically independent TDC (A, B) and AMPY (A, B) molecules. The two molecules adopt similar geometry and supramolecular interactions. In the crystal two individual trimers are formed as a result of hydrogen-bond interactions between the two carboxylic acid groups and pyrimidine groups (A molecule of TDC with that of A molecule of AMPY, B molecule of TDC with that of B molecule of AMPY) (Figure 5a). Due to the presence of two carboxylic acid groups of the TDC the chain extends along the $\mathrm{b}$ axis. There are stacking interactions observed between the AMPY of A chain and AMPY of $B$ chain, similarly, stacking interactions are observed between TDC of A chain and TDC of B chain (Figure 5a).
Two of the AB chains are again connected to an $A B$ chain which are parallel to each other by stacking interaction between the thiophene ring of A chains. This leads to a wavy sheet like arrangement extending along the $b$ axis (Figure 5b).

\section{Crystal structure description of 5TPCCYT (4a)}

The asymmetric unit of (4a) consists of a cytosine (CYT), a protonated cytosine $\left(\mathrm{CYTH}^{+}\right)$and a carboxylate anion. Usually the cytosine gets protonated at N3 and the protonated form $\left(\mathrm{CYTH}^{+}\right)$can interact with the neutral cytosine (CYT) through a set of three hydrogen bonds generating a $\left(\mathrm{CYTH}^{+} \ldots \mathrm{CYT}\right)$ motif as shown in. In the cytosine molecule, protonation at N3 leads to widening of C4-N3-C2 angle from $120.05^{\circ}$ to $123.19^{\circ}[33,34]$.

The protonated cytosine $(\mathrm{CYTH}+)$, and the cytosine (CYT) are linked via triple hydrogen bonds made up of two N-H...O and a N-H...N hydrogen bond (Figure 6a). This $\mathrm{CYT}^{-\mathrm{CYTH}^{+}}$base pair has also been observed in many crystal structures $[35,36]$. These CYT-CYTH + base pairs are further linked via N-H...O hydrogen bonds leading to chains of base pairs. Such chains running parallel to one another are stacked to the other chain by a pair of $\pi-\pi$ stacking interactions between the protonated cytosine $(\mathrm{CYTH}+)$ of one chain and the neutral cytosine (CYT) of the other chain (Figure 6a).

Also a pair of strong N-H...O hydrogen bonds between the carboxylate anion and $(\mathrm{CYTH}+$ of one chain as well 
Table 3 Hydrogen bond metrics for compounds $\mathbf{1 a - 7 b}$

\begin{tabular}{|c|c|c|c|c|}
\hline $\mathrm{D}-\mathrm{H} . . . . \mathrm{A}$ & H...A (Á) & D...A (Á) & D -H...A & Symmetry operation \\
\hline \multicolumn{5}{|l|}{ 5TPC AMPY (1a) } \\
\hline $\mathrm{O} 1 \mathrm{~A}-\mathrm{H} 1 \mathrm{~A} \cdots \mathrm{N} 1 \mathrm{~B}$ & $1.66(4)$ & $2.636(4)$ & 172(3) & \\
\hline $\mathrm{O} 3 \mathrm{~A}-\mathrm{H} 3 \mathrm{~A} \cdots \mathrm{N} 3 \mathrm{~B}$ & $1.70(4)$ & 2.682(3) & $178(4)$ & \\
\hline $\mathrm{N} 4 \mathrm{~B}-\mathrm{H} 3 \mathrm{C} \cdots \mathrm{O} 2 \mathrm{~A}$ & 2.08 & $2.928(4)$ & 170 & \\
\hline N4B-H3D $\cdots O 4 A$ & 2.05 & $2.902(4)$ & 171 & \\
\hline $\mathrm{C} 8 \mathrm{~A}-\mathrm{H} 8 \mathrm{~A} \cdots \mathrm{O} 4 \mathrm{~A}$ & 2.55 & $3.419(5)$ & 155 & $1-x,-y, 1-z$ \\
\hline $\mathrm{C} 8 \mathrm{~B}-\mathrm{H} 8 \mathrm{E} \cdots \mathrm{O} 4 \mathrm{~A}$ & 2.60 & $3.495(5)$ & 156 & $1-x, 1-y, 1-z$ \\
\hline C-X...Cg & $X \ldots C g(\AA ̊)$ & C-X...Cg $\left(^{\circ}\right)$ & Y..Cg (Å) & Symmetry code \\
\hline C5A-Cl1A Cg3 & $3.7555(19)$ & $92.33(12)$ & $4.190(4)$ & $-1+X, 1 / 2-Y,-1 / 2+Z$ \\
\hline $\mathrm{C} 10 \mathrm{~A}-\mathrm{Cl} 2 \mathrm{~A} \mathrm{Cg} 2$ & $3.9862(19)$ & $88.75(14)$ & $4.302(4)$ & $1+X, 1 / 2-Y, 1 / 2+Z$ \\
\hline \multicolumn{5}{|l|}{ TPCAMPY(2a) } \\
\hline $\mathrm{N} 1 \mathrm{~B}-\mathrm{H} 1 \mathrm{~B} \cdots \mathrm{O} 2 \mathrm{~A}$ & 1.74 & $2.593(4)$ & 171 & \\
\hline $\mathrm{N} 4 \mathrm{~B}-\mathrm{H} 4 \mathrm{C} \cdots \mathrm{N} 3 \mathrm{~B}$ & 2.19 & $3.043(5)$ & 171 & $-x, 1-y, 2-z$ \\
\hline 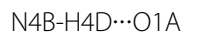 & 2.08 & $2.912(4)$ & 164 & \\
\hline $\mathrm{C} 5 \mathrm{~A}-\mathrm{H} 5 \mathrm{~A} \cdots \mathrm{O} 1 \mathrm{~A}$ & 2.51 & $3.417(4)$ & 165 & $x, 1 / 2-y,-1 / 2+z$ \\
\hline \multicolumn{5}{|l|}{ TDCAMPY(3a) } \\
\hline $\mathrm{N} 4 \mathrm{C}-\mathrm{H} 4 \mathrm{E} \cdots \mathrm{O} 2 \mathrm{~A}$ & 2.07 & $2.926(3)$ & 173 & $1-x,-1 / 2+y, 3 / 2-z$ \\
\hline $\mathrm{N} 4 \mathrm{C}-\mathrm{H} 4 \mathrm{~F} \cdots \mathrm{O} 4 \mathrm{~A}$ & 2.00 & $2.853(3)$ & 171 & \\
\hline $\mathrm{N} 4 \mathrm{D}-\mathrm{H} 4 \mathrm{H} \cdots \mathrm{O} 2 \mathrm{~B}$ & 2.04 & 2.897(3) & 174 & \\
\hline $\mathrm{N} 4 \mathrm{D}-\mathrm{H} 4 \mid \cdots \mathrm{O} 4 \mathrm{~B}$ & 2.08 & 2.933(3) & 171 & $2-x_{,}-1 / 2+y, 1 / 2-z$ \\
\hline $\mathrm{O} 1 \mathrm{~A}-\mathrm{H} 11 \mathrm{~A} \cdots \mathrm{N} 3 \mathrm{C}$ & $1.83(3)$ & $2.608(3)$ & $166(3)$ & $1-x, 1 / 2+y, 3 / 2-z$ \\
\hline 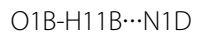 & $1.96(3)$ & $2.660(3)$ & $171(3)$ & \\
\hline $\mathrm{O} 3 \mathrm{~A}-\mathrm{H} 33 \mathrm{~A} \cdots \mathrm{N} 1 \mathrm{C}$ & $1.67(3)$ & 2.643(3) & $177(3)$ & \\
\hline 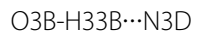 & $1.69(3)$ & $2.636(3)$ & $167(3)$ & $2-x, 1 / 2+y, 1 / 2-z$ \\
\hline \multicolumn{5}{|l|}{ 5TPC CYT(4a) } \\
\hline $\mathrm{N} 1 \mathrm{~A}-\mathrm{H} 1 \mathrm{~A} \cdots \mathrm{O} 2$ & 1.96 & 2.759(3) & 154 & $1-x, 2-y, 1-z$ \\
\hline $\mathrm{N} 1 \mathrm{~B}-\mathrm{H} 1 \mathrm{~B} \cdots \mathrm{O} 1$ & 1.76 & $2.6194(18)$ & 172 & \\
\hline $\mathrm{N} 3 \mathrm{~B}-\mathrm{H} 3 \mathrm{~B} \cdots \mathrm{N} 3 \mathrm{~A}$ & 2.00 & $2.8586(17)$ & 177 & \\
\hline $\mathrm{N} 4 \mathrm{~A}-\mathrm{H} 4 \mathrm{C} \cdots \mathrm{O} 3 \mathrm{~B}$ & 2.06 & 2.9234(19) & 176 & \\
\hline $\mathrm{N} 4 \mathrm{~A}-\mathrm{H} 4 \mathrm{D} \cdots \mathrm{O} 3 \mathrm{~A}$ & 2.15 & $2.8632(19)$ & 140 & $x_{,}-1+y, z$ \\
\hline $\mathrm{N} 4 \mathrm{~B}-\mathrm{H} 4 \mathrm{E} \cdots \mathrm{O} 3 \mathrm{~A}$ & 1.92 & $2.7836(19)$ & 177 & \\
\hline $\mathrm{N} 4 \mathrm{~B}-\mathrm{H} 4 \mathrm{~F} \cdots \mathrm{O} 3 \mathrm{~B}$ & 2.09 & $2.8626(18)$ & 149 & $x, 1+y, z$ \\
\hline C-X...Cg & X...Cg (Å) & C-X...Cg $\left(^{\circ}\right)$ & Y..Cg (Å) & Symmetry code \\
\hline $\mathrm{C} 5-\mathrm{Cl} 1 \mathrm{Cg} 3$ & $3.6501(10)$ & $97.03(7)$ & $4.220(2)$ & $-X, 1-Y,-Z$ \\
\hline $\mathrm{C} 1-\mathrm{O} 1 \mathrm{Cg} 2$ & $3.4019(16)$ & $141.27(12$ & $4.460(2)$ & $-X, 2-Y, 1-Z$ \\
\hline $\mathrm{C} 2 \mathrm{~A}-\mathrm{O} 3 \mathrm{~A} \mathrm{Cg} 1$ & $3.4771(14)$ & 69.46(9) & $3.2563(16)$ & $1-X, 2-Y, 1-Z$ \\
\hline \multicolumn{5}{|l|}{ 5TPC BA(5a) } \\
\hline $\mathrm{N} 1-\mathrm{H} 1 \cdots \mathrm{O} 1$ & $2.00(6)$ & $2.886(7)$ & $169(7)$ & $-1+x, y, z$ \\
\hline $\mathrm{O} 2-\mathrm{H} 2 \mathrm{~A} \cdots \mathrm{N} 5$ & $1.85(6)$ & $2.631(6)$ & 173(8) & $1+x, y, z$ \\
\hline 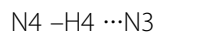 & $1.89(6)$ & $2.886(7)$ & $169(6)$ & $1-x,-y, 1-z$ \\
\hline $\mathrm{C} 8-\mathrm{H} 8 \cdots \mathrm{N} 1$ & 2.54 & $2.875(8)$ & 101 & \\
\hline $\mathrm{C} 11-\mathrm{H} 11 \cdots \mathrm{O} 2$ & 2.60 & $3.479(9)$ & 158 & $x, 1+y, z$ \\
\hline
\end{tabular}


Table 3 Hydrogen bond metrics for compounds 1a-7b (Continued)

\begin{tabular}{|c|c|c|c|c|}
\hline$C-X \ldots C g$ & X...Cg $(\AA ̊)$ & C-X...Cg $\left({ }^{\circ}\right)$ & Y..Cg (Å) & Symmetry code \\
\hline C5A-Cl1A Cg3 & $3.874(3)$ & $127.9(3)$ & $5.105(7)$ & $-1-X, 1-Y, 2-Z$ \\
\hline $\mathrm{C} 1 \mathrm{~A}-\mathrm{O} 2 \mathrm{~A} \mathrm{Cg} 1$ & $3.945(5)$ & 63.4(3) & $3.571(6)$ & $-1+X, Y, Z$ \\
\hline $\mathrm{C} 1 \mathrm{~A}-\mathrm{O} 2 \mathrm{~A}$ Cg5 & $3.962(5)$ & $69.1(3)$ & $3.707(6)$ & $1+X, Y, Z$ \\
\hline \multicolumn{5}{|l|}{ 5TPC2NPY(6a) } \\
\hline $\mathrm{N} 1 \mathrm{~B}-\mathrm{H} 1 \mathrm{~B} \cdots \mathrm{O} 1 \mathrm{~A}$ & 1.82 & $2.6667(17)$ & 169 & \\
\hline $\mathrm{N} 2 \mathrm{~B}-\mathrm{H} 2 \mathrm{C} \cdots \mathrm{O} 2 \mathrm{~A}$ & 1.94 & $2.7861(19)$ & 169 & \\
\hline $\mathrm{N} 2 \mathrm{~B}-\mathrm{H} 2 \mathrm{D} \cdots \mathrm{O} 1 \mathrm{~A}$ & 2.03 & 2.8873(19) & 172 & $x, 3 / 2-y, 1 / 2+z$ \\
\hline $\mathrm{C} 2 \mathrm{~B}-\mathrm{H} 2 \mathrm{~B} \cdots \mathrm{O} 2 \mathrm{~A}$ & 2.48 & $3.211(2)$ & 135 & $1-x, 1 / 2+y, 3 / 2-z$ \\
\hline$C-X \ldots C g$ & X...Cg (Å) & C-X...Cg $\left({ }^{\circ}\right)$ & Y..Cg (Å) & Symmetry code \\
\hline C3B-H3B Cg2 & 2.93 & 133 & $3.628(2)$ & $1+X, 3 / 2-Y, 1 / 2+Z$ \\
\hline \multicolumn{5}{|l|}{ 5TPC ACR(7a) } \\
\hline $\mathrm{O} 1 \mathrm{~A}-\mathrm{H} 1 \mathrm{~A} \cdots \mathrm{N} 1 \mathrm{~B}$ & 1.721(19) & $2.574(2)$ & $168(2)$ & \\
\hline
\end{tabular}

Table 4 Hydrogen bond metrics for compounds $\mathbf{8 b}-\mathbf{1 4 b}$

\begin{tabular}{|c|c|c|c|c|}
\hline D--H....A & H...A (Á) & D...A (Á) & D -H...A & Symmetry operation \\
\hline \multicolumn{5}{|c|}{ 5TPC44BIPY (8b) } \\
\hline $\mathrm{O} 1-\mathrm{H} 1 \cdots \mathrm{N} 1$ & 1.77 & $2.6543(16)$ & 179 & \\
\hline \multicolumn{5}{|c|}{ TPC44BIPY(9b) } \\
\hline $\mathrm{O} 1-\mathrm{H} 1 \cdots \mathrm{N} 1$ & $1.76(3)$ & 2.629(3) & $178(3)$ & \\
\hline \multicolumn{5}{|c|}{ 5ТРC44TMBP(10b) } \\
\hline $\mathrm{O} 1-\mathrm{H} 1 \cdots \mathrm{N} 1$ & $1.63(4)$ & $2.576(3)$ & $171(3)$ & \\
\hline $\mathrm{C} 9-\mathrm{H} 9 \cdots \mathrm{O} 2$ & 2.44 & $3.350(3)$ & 166 & $1-x_{1}-1+y, 1-z$ \\
\hline C-X...Cg & $X \ldots . . . \mathrm{Cg}(\AA ̊)$ & C-X...Cg $\left(^{\circ}\right)$ & Y..Cg $(\AA)$ & Symmetry code \\
\hline $\mathrm{C} 5-\mathrm{Cl} 1 \mathrm{Cg} 2$ & $3.6338(12)$ & 90.93(8) & $4.045(3)$ & $X, 1+Y, Z$ \\
\hline \multicolumn{5}{|c|}{ TPC44TMBP(11b) } \\
\hline $\mathrm{O} 3-\mathrm{H} 1 \cdots \mathrm{N} 1$ & 1.81 & 2.592(9) & 156 & \\
\hline $\mathrm{N} 2-\mathrm{H} 2 \cdots \mathrm{O} 2$ & 1.75 & $2.569(8)$ & 171 & \\
\hline $\mathrm{C} 2 \mathrm{O}-\mathrm{H} 2 \mathrm{O} \cdots \mathrm{O} 4$ & 2.59 & $3.488(10)$ & 163 & $-1 / 2+x, 1 / 2-y, z$ \\
\hline \multicolumn{5}{|c|}{ TDC44TMBP(12b) } \\
\hline $\mathrm{N} 1-\mathrm{H} 1 \mathrm{~A} \cdots \mathrm{O} 2$ & 1.75 & $2.5883(19)$ & 165 & \\
\hline $\mathrm{O} 3-\mathrm{H} 3 \mathrm{~A} \cdots \mathrm{O} 1$ & $1.56(2)$ & $2.5439(16)$ & $176(2)$ & \\
\hline $\mathrm{C} 7-\mathrm{H} 7 \cdots \mathrm{O} 4$ & 2.42 & $3.297(2)$ & 156 & $1-x, 1-y, 1-z$ \\
\hline $\mathrm{C} 8-\mathrm{H} 8 \cdots \mathrm{O} 4$ & 2.48 & $3.368(2)$ & 161 & $1+x, y, 1+z$ \\
\hline $\mathrm{C} 11-\mathrm{H} 11 \cdots \mathrm{O} 1$ & 2.39 & $3.201(3)$ & 146 & $-x, 1-y, 1-z$ \\
\hline \multicolumn{5}{|c|}{ 5TPC44BIPZ(13b) } \\
\hline $\mathrm{N} 1-\mathrm{H} 1 \mathrm{~A} \cdots \mathrm{O} 3$ & 1.85 & $2.7396(16)$ & 167 & \\
\hline $\mathrm{N} 1-\mathrm{H} 1 \mathrm{~B} \cdots \mathrm{O} 4$ & 1.99 & $2.8852(19)$ & 159 & $2-x, 1-y, 1-z$ \\
\hline $\mathrm{O} 1-\mathrm{H} 2 \mathrm{~A} \cdots \mathrm{O} 4$ & 1.52 & $2.5202(17)$ & 172 & \\
\hline \multicolumn{5}{|c|}{ 5TPC44PYNO(14b) } \\
\hline $\mathrm{O} 1-\mathrm{H} 1 \mathrm{~A} \cdots \mathrm{O} 3$ & $1.84(5)$ & $2.560(4)$ & $171(5)$ & \\
\hline $\mathrm{C} 6-\mathrm{H} 6 \cdots \mathrm{O} 2$ & 2.39 & $3.287(5)$ & 163 & \\
\hline $\mathrm{C} 7-\mathrm{H} 7 \cdots \mathrm{O} 3$ & 2.50 & $3.381(4)$ & 158 & $x, 1 / 2-y,-1 / 2+z$ \\
\hline $\mathrm{C} 10-\mathrm{H} 10 \cdots \mathrm{O} 2$ & 2.51 & $3.308(4)$ & 144 & $x, 1 / 2-y, 1 / 2+z$ \\
\hline
\end{tabular}




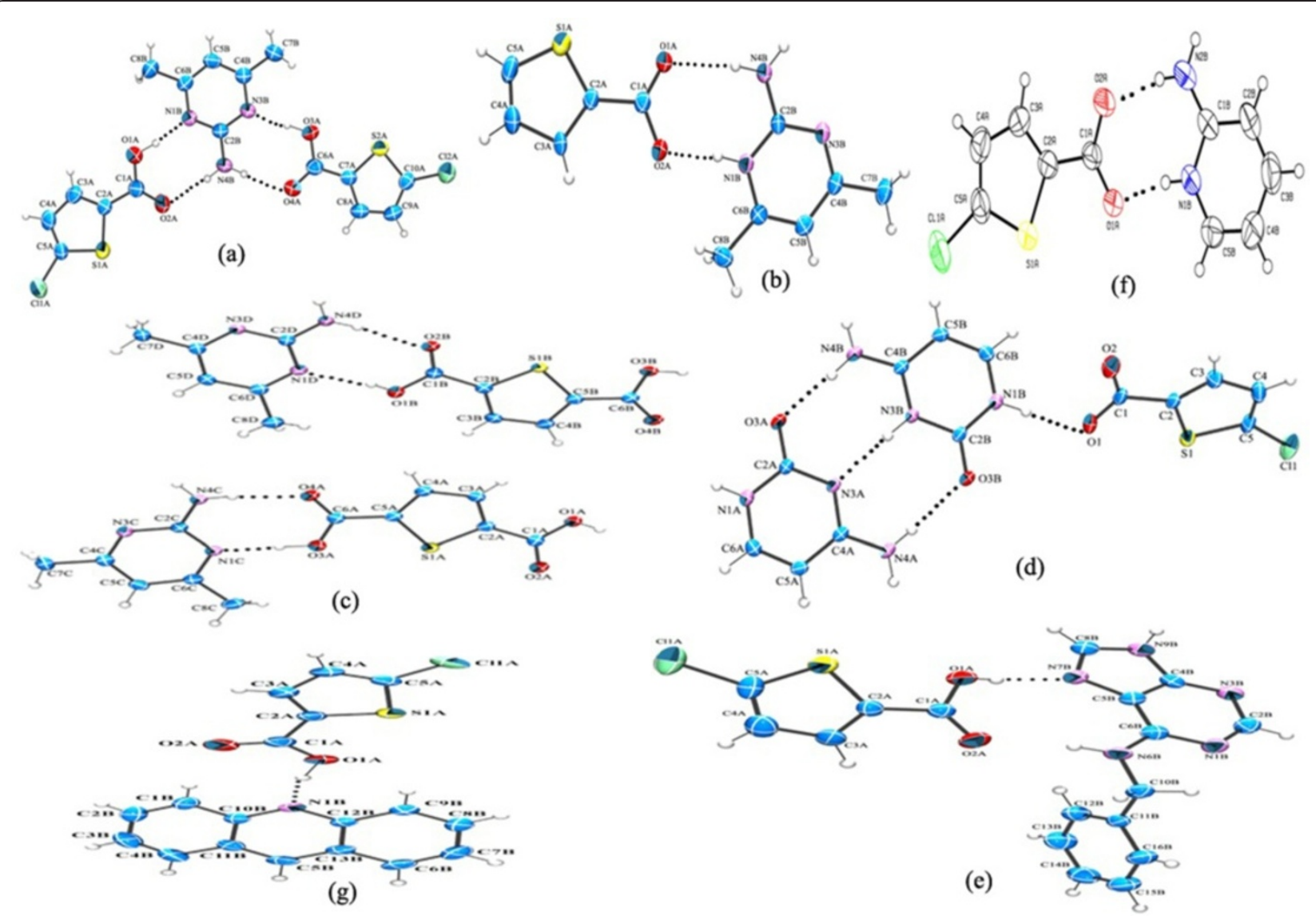

Figure 1 (a-g) ORTEP views of compounds 1a-7a showing the atom-numbering scheme. Displacement ellipsoids drawn at 50\% probability level for all non hydrogen atoms and $\mathrm{H}$ atoms are shown as small spheres of arbitrary radii.

as neutral cytosine (CYT) of the other chain) hold the chains together. This carboxylate anion plays a major role in connecting the chains together. $\mathrm{A} \mathrm{Cl}$... $\pi$ is observed between chlorine of thiophene ring of a chain and the thiophene ring of the adjacent chain (Figure 6b).

\section{Crystal structure description of 5TPCBA (5a)}

The compound (5a) crystallizes in P-1 triclinic spacegroup, where the asymmetric unit consists of one molecule of BA and a molecule of 5TPC. The dihedral angle between the adenine plane and phenyl ring plane is $87.2(3)^{\circ}$. The primary $\mathrm{R}_{2}{ }^{2}(9)$ motif is composed of 5TPC and BA which are connected through a couple of strong O-H...N and N-H...O hydrogen bonds (Figure 7a). This motif is very much similar to that observed in the related structures [37-39]. Adjacent dimeric units are further connected through self complementary secondary $\mathrm{N}-\mathrm{H} \cdots \mathrm{N}$ hydrogen bonds. The hydrogen of the phenyl ring and the carboxylic acid oxygen interact in a C-H...O hydrogen bond (Figure 7a). Thus the primary and secondary hydrogen bonds, $\mathrm{O}-\mathrm{H} \cdots \mathrm{N}, \mathrm{N}-\mathrm{H} \cdots \mathrm{O}, \mathrm{N}-\mathrm{H} \cdots \mathrm{N}$ and $\mathrm{C}-\mathrm{H} . . \mathrm{O}$ combine to form a tetrameric super molecule
(Figure 7a). Each of these tetrameric super molecules is linked by $\mathrm{C}-\mathrm{H}$... O interactions. As in the (4a), the $\mathrm{Cl}$ of the 5-TPC plays a major role in building of the supramolecular architectures. The adjacent chains made of the tetrameric super molecules are linked to one another by the $\mathrm{Cl} \ldots \pi$ interactions between $\mathrm{Cl}$ of 5-TPC of one chain and the phenyl ring of BA of another chain (Figure $7 \mathrm{~b}$ ).

\section{Crystal structure description of 5TPC2NPY (6a)}

The compound (6a) crystallizes in monoclinic $\mathrm{P} 2{ }_{1} / \mathrm{c}$ space group with the asymmetric unit possessing a molecule of $5 \mathrm{TPC}^{-}$carboxylate anion and a molecule of $2 \mathrm{NPY}^{+}$pyridinium cation. The primary motif is very similar to that of (2a) and is made up of charge-assisted hydrogen bond interactions between the carboxylate and the amino-pyridinium moieties through $\mathrm{N}-\mathrm{H} \cdots \mathrm{O}^{-}$and $\mathrm{N}-\mathrm{H}^{+} \ldots \mathrm{O}^{-}$hydrogen bonds (Figure 8). These interactions act as the primary hydrogen bonds and are responsible for the $R_{2}{ }^{2}(8)$ ring motif between them. There is a $\pi-\pi$ stacking interaction observed between the $2 \mathrm{NPY}^{+}$pyridinium cations (Figure 8 ). The $\mathrm{C}-\mathrm{H} . . . \mathrm{Cl}$ interactions are found between the $\mathrm{Cl}$ of a 5-TPC and $\mathrm{H}$ of the thiophene ring (Figure 8). 


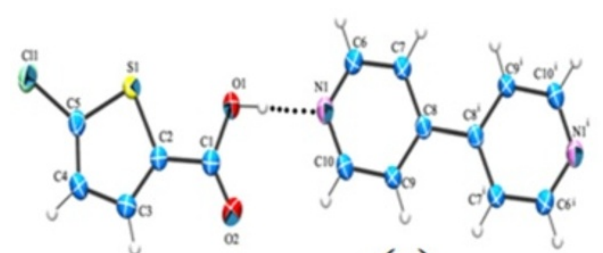

(a)

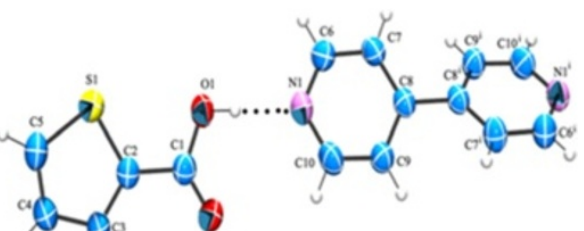

(b)

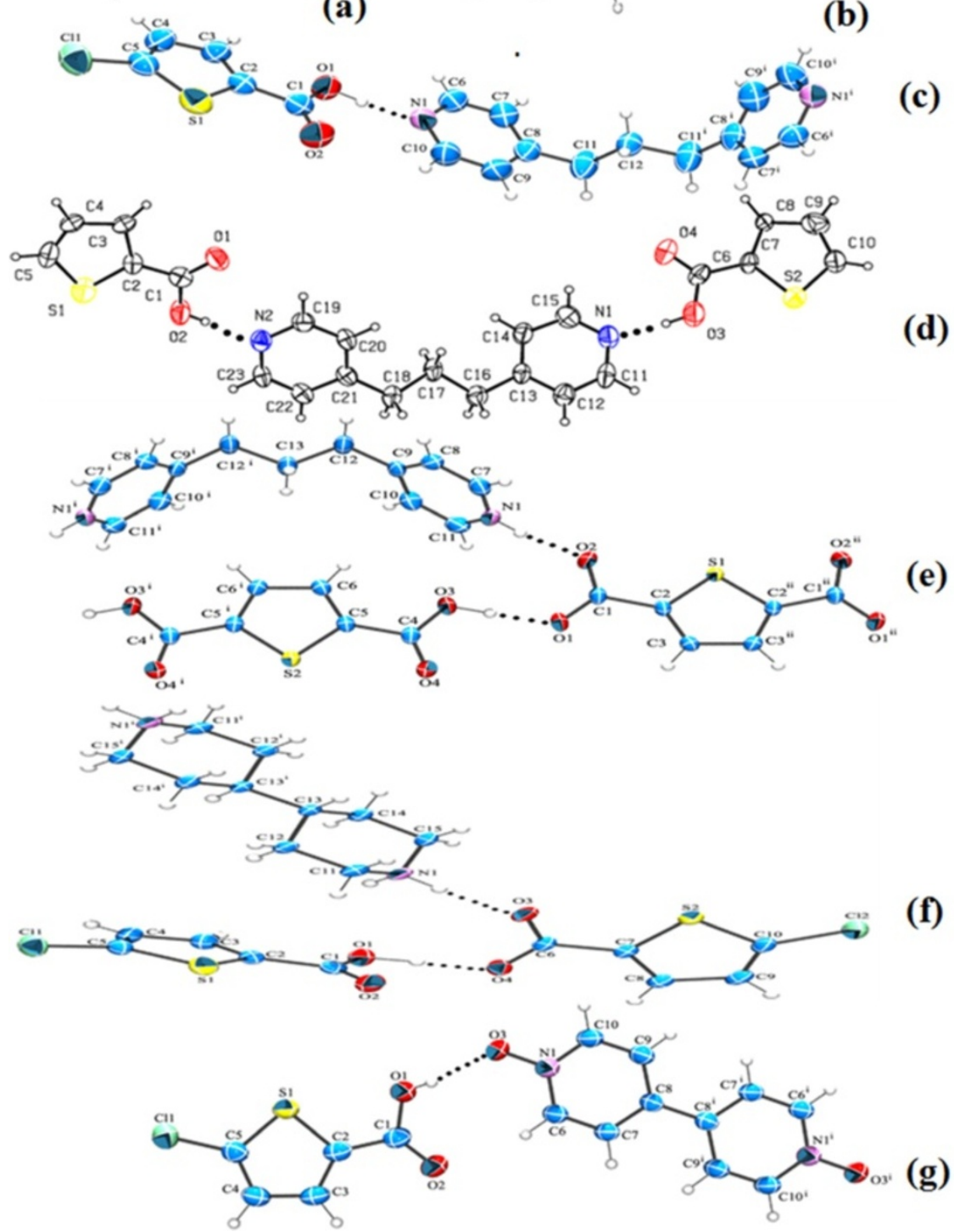

Figure 2 (a-g) ORTEP views of compounds $\mathbf{8 b}$-14b showing the atom-numbering scheme. Displacement ellipsoids drawn at 50\% probability level for all non hydrogen atoms and $\mathrm{H}$ atoms are shown as small spheres of arbitrary radii.

\section{Crystal structure description of 5TPCACR (7a)}

The compound (7a) was cocrystallized from methanol and contains a 1:1 mixture of 5-TPC and ACR. O-H $\cdots \mathrm{N}$ interactions are found between carboxylic acid and the nitrogen containing heterocyclic ring of the acridine. The crystal structure is further stabilized by $\mathrm{C}-\mathrm{H} \cdots \pi$ interactions. The $\mathrm{O}-\mathrm{H} \cdots \mathrm{N}$ hydrogen bond is found between $\mathrm{H} 1 \mathrm{~A}$ of the carboxylic acid and the N1B nitrogen atom of the acridine (Figure 2a). $\pi-\pi$ stacking interactions are found between two oppositely oriented consecutive acridine molecules. Four $\pi-\pi$ stacking interactions such as $\mathrm{Cg} 1 \rightarrow \mathrm{Cg}^{\mathrm{v}}, \mathrm{Cg} 1 \rightarrow \mathrm{Cg}^{2}, \mathrm{Cg} 2 \rightarrow \mathrm{Cg}^{\mathrm{v}} \quad \& \quad \mathrm{Cg} 1 \rightarrow \mathrm{Cg} 3^{\text {iv }}$ (Symmetry codes:(iv) $-\mathrm{x}+1,-\mathrm{y}+2,-\mathrm{z}$; (v) $-\mathrm{x},-\mathrm{y}+2,-\mathrm{z}$ ) stack the acridine molecules (Figure $2 \mathrm{a})(\mathrm{Cg} 1=$ centroid of ring $\mathrm{N} 1 \mathrm{~B} / \mathrm{C} 10 \mathrm{~B} / \mathrm{C} 11 \mathrm{~B} / \mathrm{C} 5 \mathrm{~B} / \mathrm{C} 13 \mathrm{~B} / \mathrm{C} 12 \mathrm{~B}, \quad \mathrm{Cg} 2=$ centroid of ring $\mathrm{C} 1 \mathrm{~B} / \mathrm{C} 2 \mathrm{~B} / \mathrm{C} 3 \mathrm{~B} / \mathrm{C} 4 \mathrm{~B} / \mathrm{C} 11 \mathrm{~B} / \mathrm{C} 10 \mathrm{~B} \mathrm{Cg} 3=$ centroid of ring $\mathrm{C} 6 \mathrm{~B} / \mathrm{C} 7 \mathrm{~B} / \mathrm{C} 8 \mathrm{~B} / \mathrm{C} 9 \mathrm{~B} / \mathrm{C} 12 \mathrm{~B} / \mathrm{C} 13 \mathrm{~B})$. These $\pi-\pi$ stacking interactions of acridine molecules which are also 
<smiles>O=C(O)c1cccs1</smiles>

TPC<smiles>Nc1ccnc(=O)[nH]1</smiles>

CYT<smiles>O=C(O)c1ccc(Cl)s1</smiles>

5TPC<smiles>O=C(O)c1ccc(C(=O)O)s1</smiles>

TDC<smiles>Nc1ccccn1</smiles>

2NPY

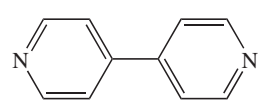

44BIPY

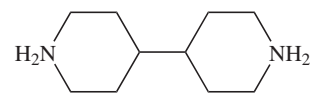

$44 \mathrm{BIPZ}$<smiles>c1ccc(CNc2ncnc3nc[nH]c23)cc1</smiles>

BA<smiles>Cc1cc(C)nc(N)n1</smiles>

AMPY<smiles>c1ccc2nc3ccccc3cc2c1</smiles>

ACR

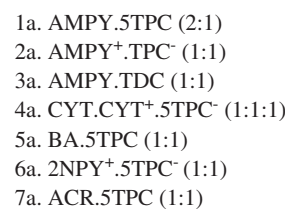

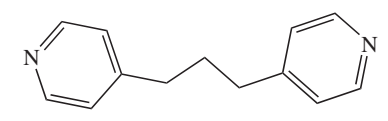

44TMBP

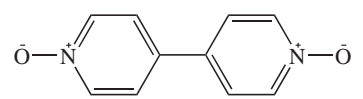

44PYNO

8b. 44BIPY.5TPC (1:1)

9b. 44BIPY.TPC $(1: 1)$

10b. 44TMBP.5TPC $(1: 1)$

11b. 44TMBP.TPC.TPC $(1: 1: 1)$

12b. 44TMBP+.TDC.TDC- $(1: 1: 1)$

13b. 44BIPZ .5 TPC. $^{+}$TPC $^{-}(1: 1: 1)$

14b. 44PYNO.5TPC (1:1)

TPC $=$ Thiophene Carboxylic acid

5TPC $=5$-Chloro thiophene 2 - carboxylic acid

TDC $=2,5$ - thiophene dicarboxylic acid

2NPY=2-Amino Pyridine

CYT=Cytosine

$\mathrm{BA}=\mathrm{N} 6$ Benzyl adenine

AMPY = 2-amino-4,6-dimethylpyrimidine

$\mathrm{ACR}=$ Acridine

44BIPY = 4,4'-Bipyridine

44PYNO = 4,4'-Bipyridine 1,1'-Dioxide

44BIPZ = 4,4'-Bipiperidine

44TMBP $=4,4^{\prime}$-Trimethylene Bipyridine

Scheme 3 Molecular structures of components used in 1-14.

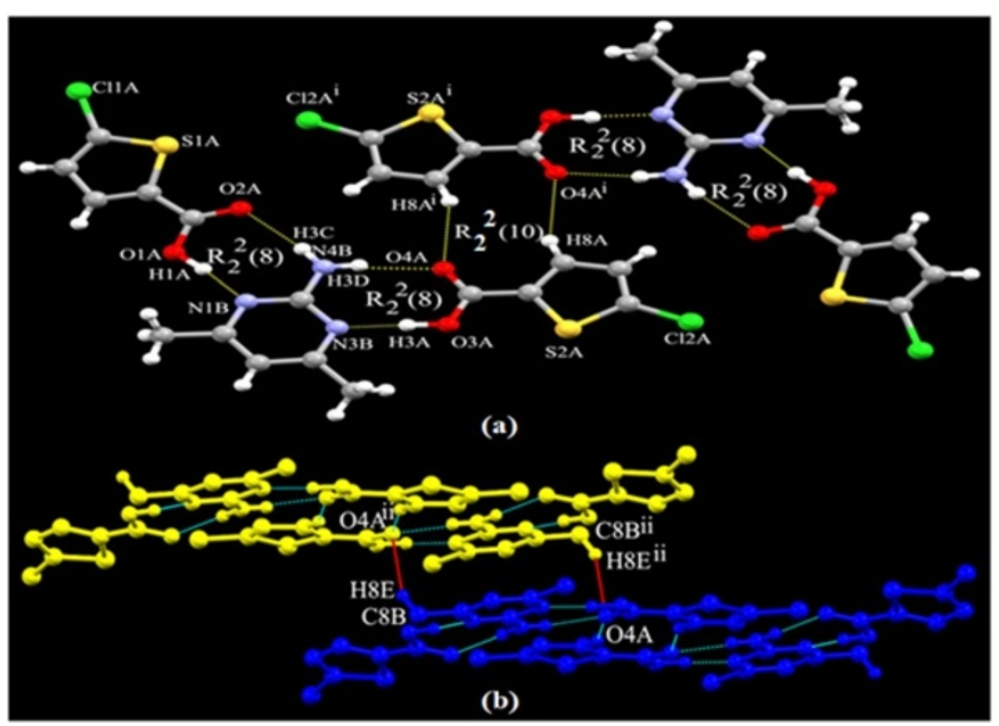

Figure 3 (a) Formation of hexameric super molecule in (1a) by the $\mathrm{N}-\mathrm{H} . . . \mathrm{O}$ and C-H...O hydrogen bonds. (b) Hexameric super molecule of one plane (yellow) linked to the similar kind of hexameric super molecule in another plane (blue) linked by soft C-H...O hydrogen bonds (red dotted lines). 


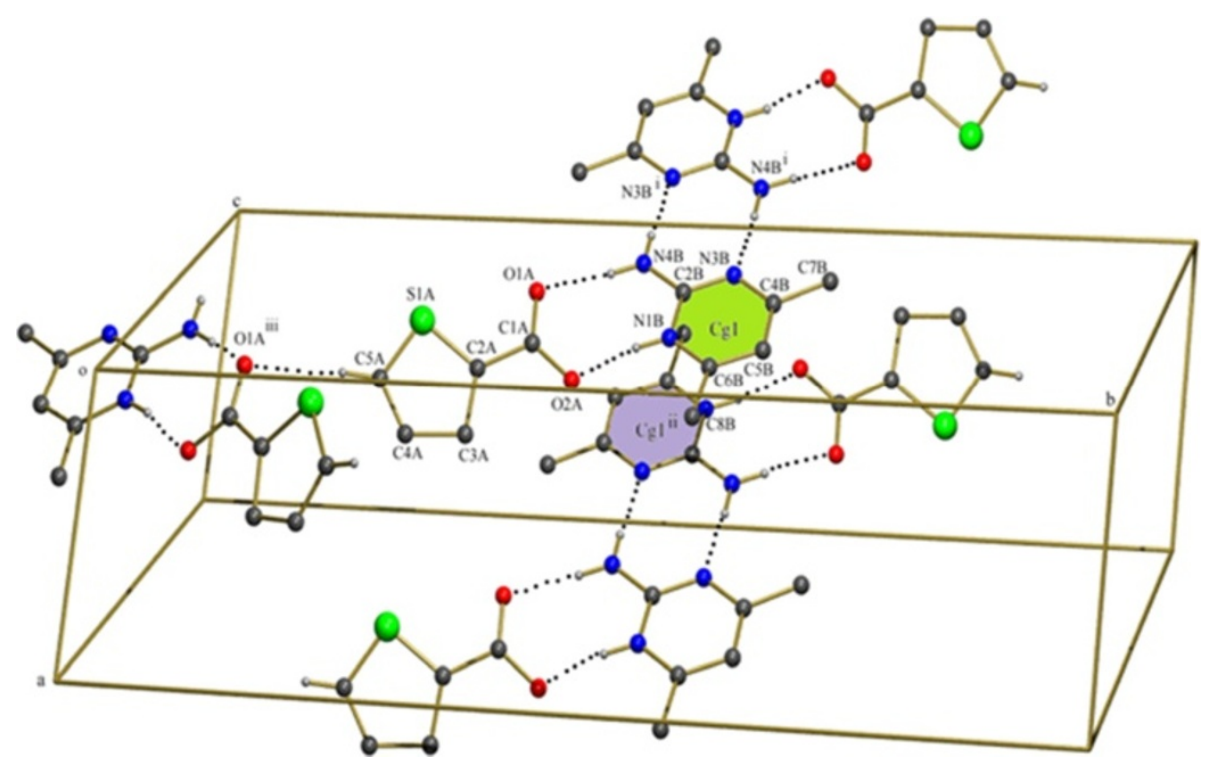

Figure 4 Formation of $\mathrm{R}_{2}{ }^{2}(8)$ moieties in $2 \mathrm{a}$ and the formation of LHT.

hydrogen bonded to carboxylic acids form a chain along the a axis (Figure 2a). These adjacent chains are cross-linked via intermolecular $\mathrm{C}-\mathrm{H} \cdots \pi$ interactions involving the $\mathrm{S} 1 \mathrm{~A} / \mathrm{C} 2 \mathrm{~A}-\mathrm{C} 5 \mathrm{~A}$ thiophene ring (centroid Cg4) (Figure 2b).

\section{Crystal structure description of 5TPC44BIPY and TPC44BIPY $(8 b, 9 b)$}

The ORTEP views of 5TPC44BIPY and TPC44BIPY are shown in (Figure 9a and b). The asymmetric unit of (8b) is composed of one molecule of 5-TPC and half molecule of 44BIPY. Similarly the asymmetric unit of $(\mathbf{9 b})$ is composed of one molecule of TPC and half a molecule of 44BIPY. The 44BIPY molecules in both the cases lie about an inversion centre connected by the acid molecules on either side. As expected both the compounds show the three molecules aggregate made up of 44BIPY ligands bridging the two carboxylic acids. Both the compounds reveal supramolecular adducts sustained by symmetric $\mathrm{COOH} . . . \mathrm{N}_{\text {arom }}$ supramolecular heterosynthon (Scheme 2c) (Figures 10 and 11).

But the expected $\mathrm{R}_{2}{ }^{2}(7)$ synthon (Scheme $2 \mathrm{a}$ ) that is formed predominantly between pyridine and carboxylic acid groups in similar type compounds is completely absent. This may be due to the least twisting of the carboxyl group attached to the thiophene ring. The carboxyl group is twisted with an angle of $2.6(2)^{\circ}$ and $4.0(3)^{\circ}$ in both compounds respectively, with respect to the least squares plane of the thiophene ring. The dihedral angle between the two pyridine rings is $0.0(7)^{\circ}$, $35.13(12)^{\circ}(\mathbf{8 b}$ and $\mathbf{9 b})$. The three molecule aggregates in $(\mathbf{8 b})$ are further linked to similar neighboring aggregates through strong $\mathrm{Cl}$... $\mathrm{O}$ and soft $\mathrm{C}-\mathrm{H}$...O interactions to generate two dimensional arrays in $(\mathbf{8 b})$ and (9b) respectively (Figure 10b). In both the cases the 44BIPY molecules act as rungs between the two chains which serve as uprights of a ladder. In (8b) two of these ladders are linked by weak C-H...S interactions, C7-H7....S1 (Figure 10b). Although both (8b) and (9b) form similar type of ladders, the difference lies in the type of arrangement. In (8b) all the three molecules lie in the same plane thereby shaping it into a planar ladder. But in (9b) the ladder is bridged by 44BIPY molecules and an adjacent acid which is flanked and slightly away from 44BIPY (Figures 10a and 11). The large deviation of 44BIPY in (9b) as well as the presence of $\mathrm{Cl}$ of the 5-TPC in $(\mathbf{8 b})$ are perhaps responsible for the difference in the higher level of supramolecular organization.

\section{Crystal structure description of 5TPC44TMBP and TPC44TMBP (10b, 11b)}

The ORTEP views of $(\mathbf{1 0 b})$ and $(\mathbf{1 1 b})$ are shown in (Figure $9 \mathrm{c}$ and d). The asymmetric unit of $(\mathbf{1 0 b})$ is composed of one molecule of 5TPC and half molecule of TMBP. The carboxylic acid-aromatic nitrogen heterosynthon is found on both pyridine rings of the TMBP in (10b). The crystal structure of (11b) is sustained by carboxylic acid-aromatic nitrogen heterosynthon (Scheme 2c) on both sides of the TMBP. Thus the three molecule aggregate is found in both cases. In (10b) the $\mathrm{C}-\mathrm{O}$ bond distances of the carboxylic acid are 1.212(2) $\AA$ and 1.298(3) $\AA$. The short and straight + $\mathrm{N} 2-\mathrm{H} 2 \ldots \mathrm{O} 2-$ hydrogen bond could pull that oxygen atom (O2) away from its attached carbon atom $(\mathrm{C} 1)$ while other $\mathrm{C}-\mathrm{O}$ bond strengthens and shortens to compensate, and indeed $\mathrm{C} 1-\mathrm{O} 2$ at $1.292(10) \AA$ is the longer bond. Further, the large difference between the exocyclic bond angles 

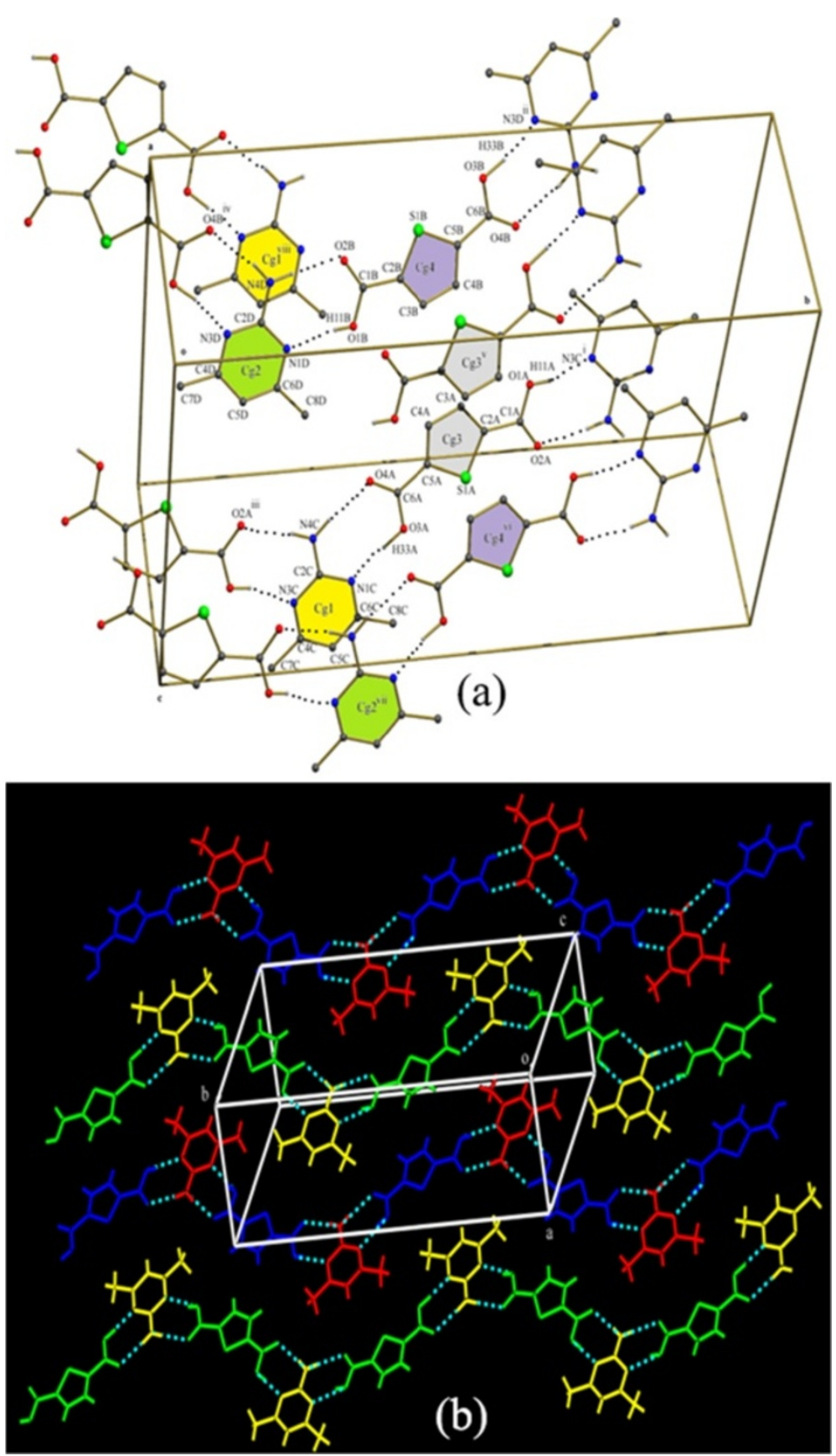

Figure 5 (a) Formation of supramolecular chains connected by stacking interactions. (b) Wavy sheet formed through weak $\mathrm{C}-\mathrm{H} \cdots \mathrm{O}$ interaction in TDCAMPY (3a).

$(\mathrm{O} 1-\mathrm{C} 1-\mathrm{C} 2=123.6(8) \AA, \mathrm{O} 2-\mathrm{C} 1-\mathrm{C} 2=112.9(7) \AA)$ of the carboxyl group confirms that it is really a carboxyl group and not a carboxylate ion. The dihedral angle between the pyridine ring/carboxylic acid is $7.5(16)^{\circ}, 2.9(4)^{\circ}$ and $7.9(4)^{\circ}$ in $(\mathbf{1 0 b})$ and $(\mathbf{1 1 b})$ respectively. The bipyridine ring is very much bent which can be noted by the very high dihedral angle between the two pyridine rings of the
TMBP $78.31(14)^{\circ}$ and $51.7(4)^{\circ}(\mathbf{1 0 b})$ and $(\mathbf{1 1 b})$ respectively. As in the case of the $(\mathbf{8 b})$ and $(\mathbf{9 b})$ the same type of ladders are formed in (10b). In (10b) the ladders are formed by $\mathrm{Cl} . . . \pi$ interactions between the adjacent 5-TPC molecules (Figure 12a).

Two of these parallel ladders are further linked by weak $\mathrm{C}-\mathrm{H}$... O interactions on both sides of the TMBP 


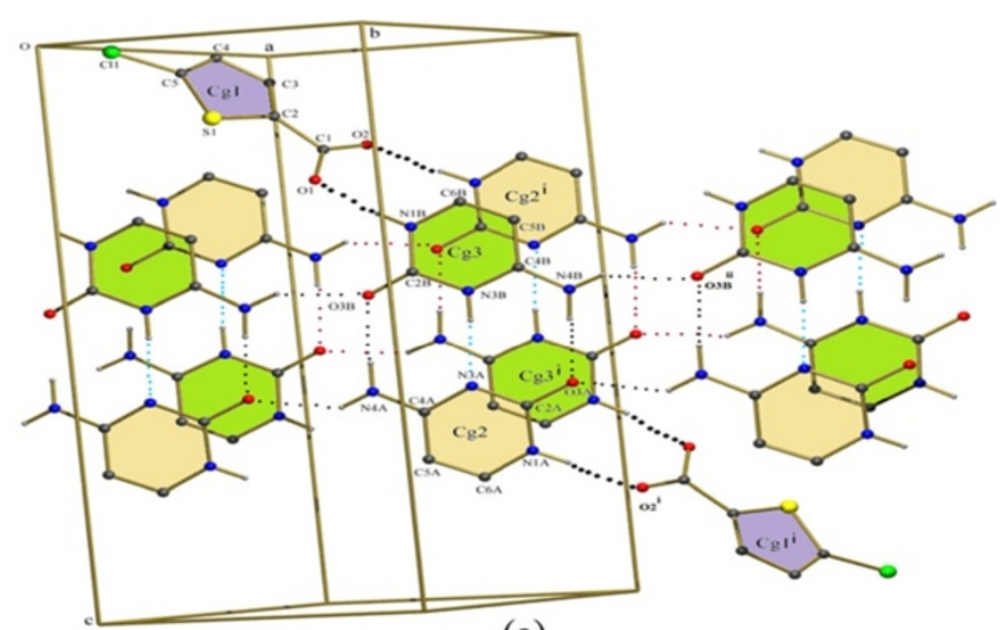

(a)

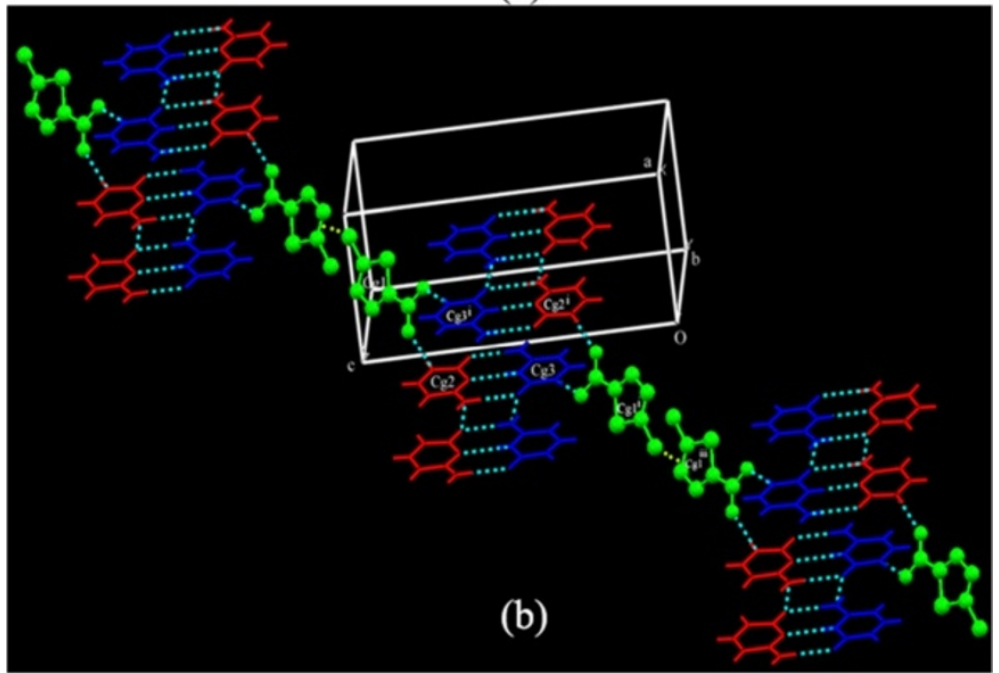

Figure 6 (a) Base pairing chains in (4a), hydrogens involved in bonding are omitted for clarity. (b) the base pairing chains linked by $\mathrm{Cl}$... interactions.

between the carboxylic acid oxygen and the hydrogen of the TMBP, leading to a herring bone like pattern in (10b) (Figure 12b).

In 11b there is a $\pi-\pi$ stacking interaction of two oppositely oriented TMBP molecules and this extends into a chain by consecutive similar type $\pi-\pi$ stacking interactions (Figure 13). Also there is a $\mathrm{C}-\mathrm{H}$... $\pi$ interaction inbetween the $\mathrm{H}$ of the pyridine ring and the oppositely oriented thiophene ring.

\section{Crystal structure description of TDC44TMBP (12b)}

The asymmetric unit of compound (12b) consists of one half of trimethylene dipyridinium cation, half a 2,5thiophenedicarboxylate anion, and half a 2,5-thiophenedicarboxylic acid. The thiophene dicarboxylic acid group possesses two functional groups capable of two-point recognition. But each of the carboxylate groups is involved in two one point supramolecular heterosynthons (Scheme 2c): one with the protonated nitrogen atom of trimethylene dipyridinium (N1-H1A...O2 = $2.5883(19) \AA)$, a second with the adjacent carboxylic acid molecule (O3-H3A...O1 $=2.5439(16) \AA)$. The C-O bond distances are 1.254(2) $\mathrm{A}, 1.251(2) \AA$, and 1.307(2) $\mathrm{A}$, $1.218(2) \AA$ for the carboxylate and carboxylic acid moiety, respectively. The $\mathrm{C}-\mathrm{N}-\mathrm{C}$ angle of the trimethylene dipyridinium is $121.83(16)^{\circ}$. The combination of these heterosynthons leads to a chain extending along the $b$ axis (Figure 14). Two of these adjacent chains are linked to each other by stacking interactions between the two TDC rings (carboxylate thiophene ring of one chain and carboxylic acid thiophene ring of another) (Figure 14). Similarly two of these chains are linked to two other chains by soft C11-H11...O1 = 3.201(3) (Symmetry code: $-x, 1-y, 1-z)$. 

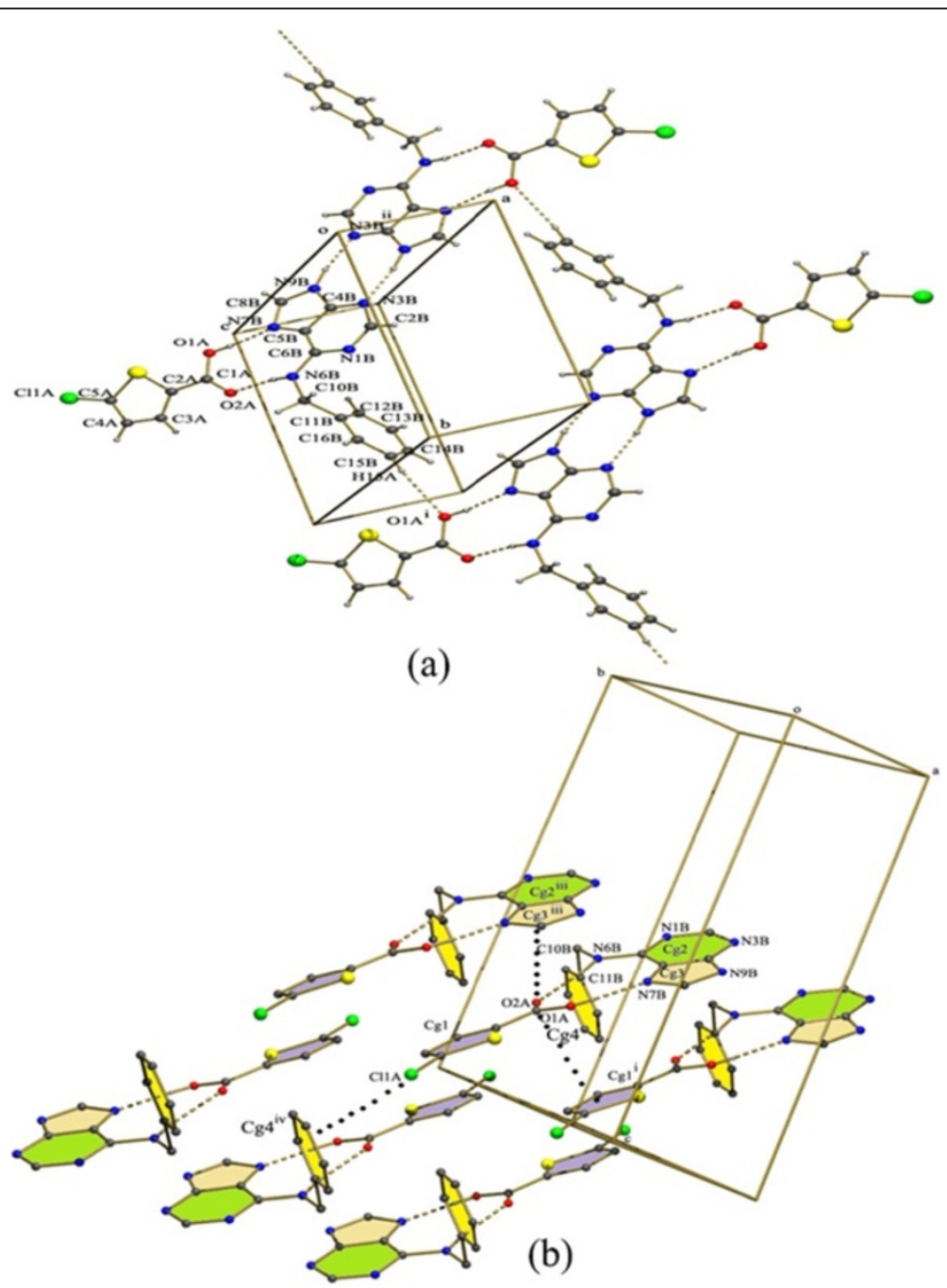

Figure 7 (a): $\mathbf{R}_{\mathbf{2}}{ }^{2}(\mathbf{9})$ motif in (5a) and the formation of tetrameric super molecule. (b) Adjacent tetrameric super molecules linked by $\mathrm{Cl} . . \pi$ interactions between $\mathrm{Cl}$ of 5-TPC of one chain and phenyl ring of BA of another chain.

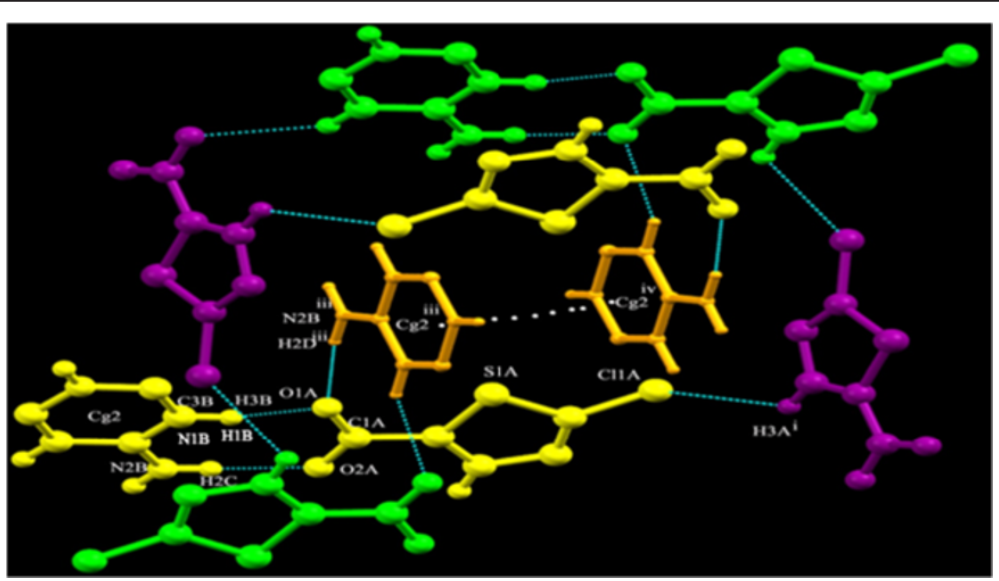

Figure $8 \pi-\pi$ stacking interaction observed between the $2 \mathrm{NPY}^{+}$pyridinium cations in (6a). 


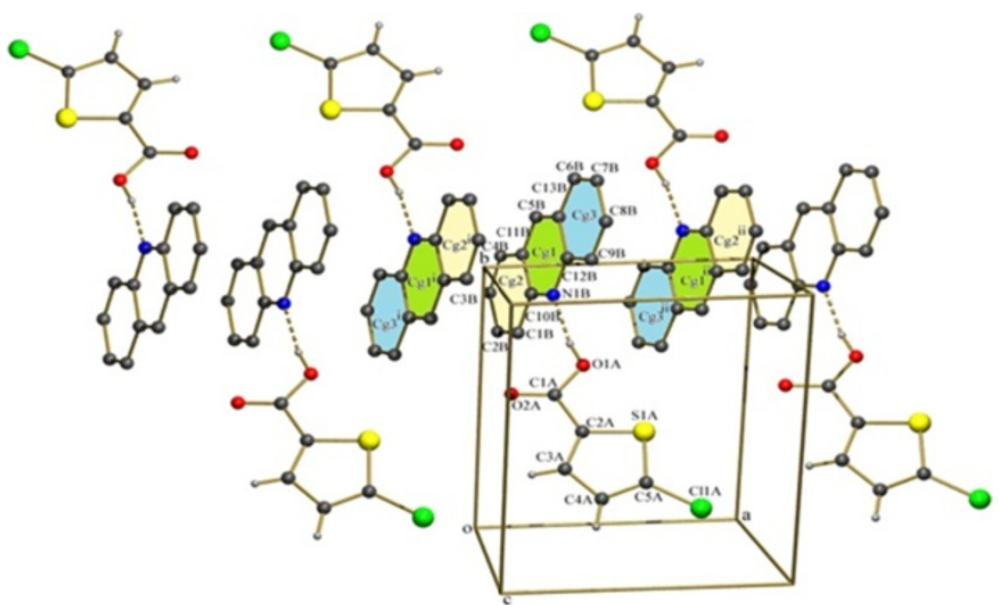

(a)

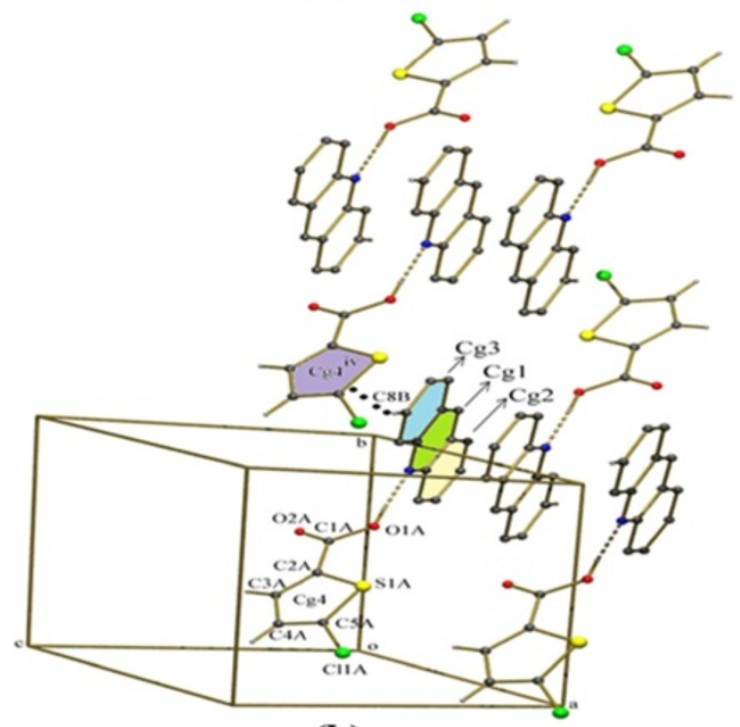

(b)

Figure 9 (a) Stacking interaction between the oppositely oriented consecutive acridine molecules in (7a). (b) Two of the adjacent chains

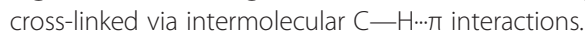

\section{Crystal structure description of 5TPC44BIPZ (13b)}

The asymmetric unit of compound (13b) consists of one half of a bipiperazinium cation, a 5-chloro-thiophene2carboxylate anion, and a 5-chloro-thiophene2-carboxylic acid. The C-O bond distances are 1.2486(19) $\AA$, 1.2696 (19) $\AA$, and 1.314(2) $\AA$, 1.208(2) $\AA$ for the carboxylate and carboxylic acid moiety, respectively. The $\mathrm{C}-\mathrm{N}-\mathrm{C}$ angle of the dipiperazinium is $111.33\left(12^{\circ}\right)$. As observed in $(\mathbf{1 2 b})$ the same two one point supramolecular heterosynthons appear (Scheme 2c): one with the protonated nitrogen atom of dipiperazinium $(\mathrm{N}(1)-\mathrm{H}(1 \mathrm{~A}) . . \mathrm{O}(3)=2.7396(16) \AA)$, a second with the adjacent carboxylic acid molecule (O1-H2A... $\mathrm{O} 4=2.5202(17) \AA)$. Another $\quad \mathrm{N} 1-\mathrm{H} 1 \mathrm{~B} . . . \mathrm{O} 4=2.8852(19)$ [symmetry code: $2-\mathrm{x}, 1-\mathrm{y}, 1-\mathrm{z}$ ] is observed between the $\mathrm{N}$ of the bipiperazinium cation and the oxygen of the carboxylate. The other end of the bipiperazinium cation containing two hydrogens is also involved in the same kind of interactions. Thus this forms a large $\mathrm{R}_{4}{ }^{4}(12)$ ring motif (Figure 15). These rings motifs extend into a chain linked by the bipiperazinium cation (Figure 15).

The carboxylic acid is linked to the carboxylate anion which is perpendicular to it (involved in formation of $\mathrm{R}_{4}{ }^{4}(12)$ ring motif) by a strong O1-H2A ...O4 $=2.5202(17)$ hydrogen bonding interaction. These carboxylic acids thus lie as pendants on both the sides to the chain made up of bipiperazinium cations. Two of these chains are again linked to one another by the stacking interactions between two carboxylic acids of each chain $\left(\mathrm{Cg} 1-\mathrm{Cg} 1^{\mathrm{iii}}\right.$ where $\mathrm{Cg} 1=\mathrm{S} 1, \mathrm{C} 2, \mathrm{C} 3, \mathrm{C} 4, \mathrm{C} 5$ [symmetry code $\mathrm{iii}=2-\mathrm{x}, 1-$ $\mathrm{y}, 1-\mathrm{z}]$ ) (Figure 16). 

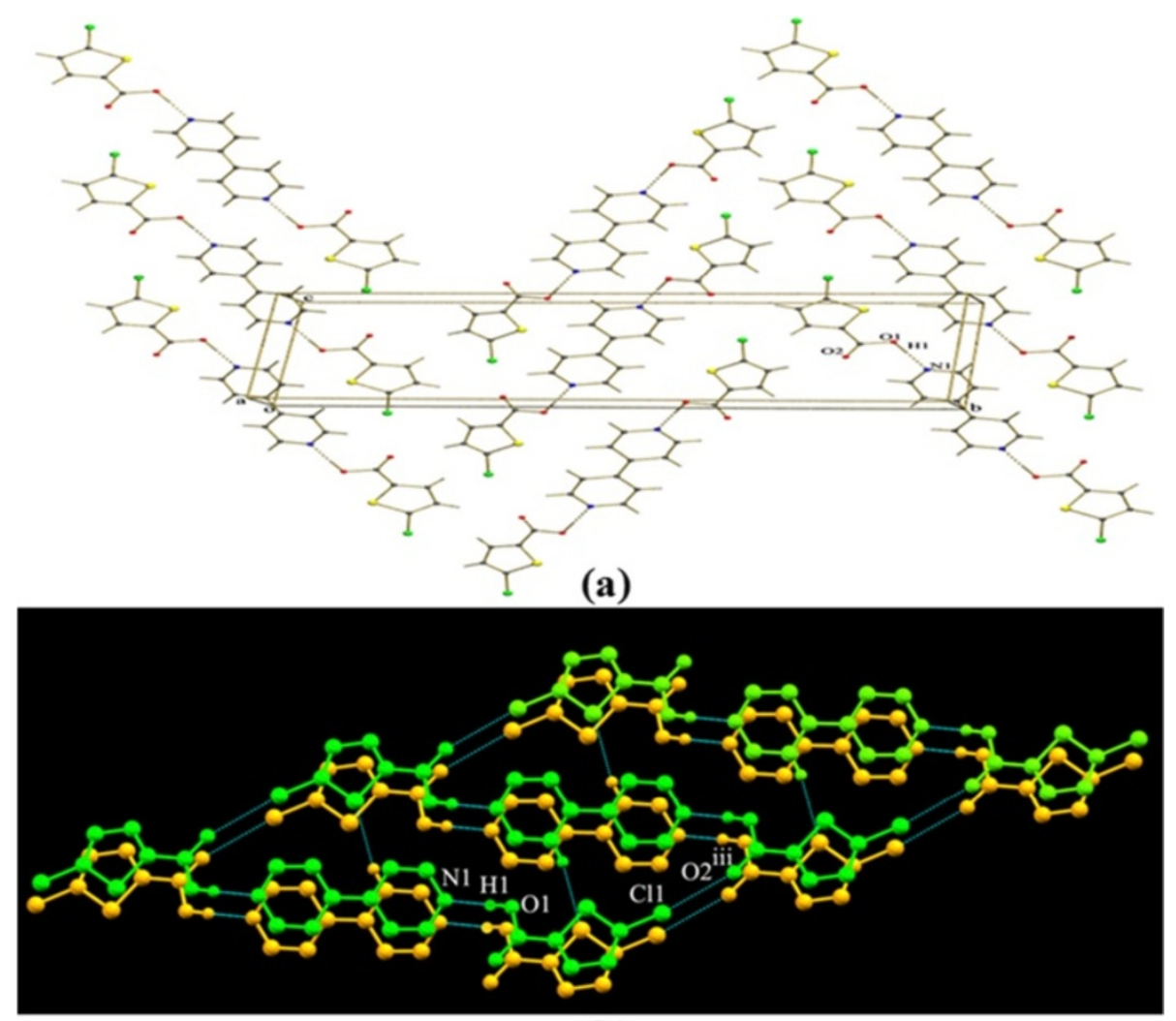

(b)

Figure 10 (a) Formation of ladder through $\mathrm{O}-\mathrm{H} . . . \mathrm{N}$ and $\mathrm{Cl}$...O bonds in (8b) where 4-4bipy acts as rungs and 5-tpc as uprights. (b) The three molecule aggregates in $8 \mathrm{~b}$ are further linked to similar neighboring aggregates through strong $\mathrm{Cl}$... $\mathrm{O}$ interactions.

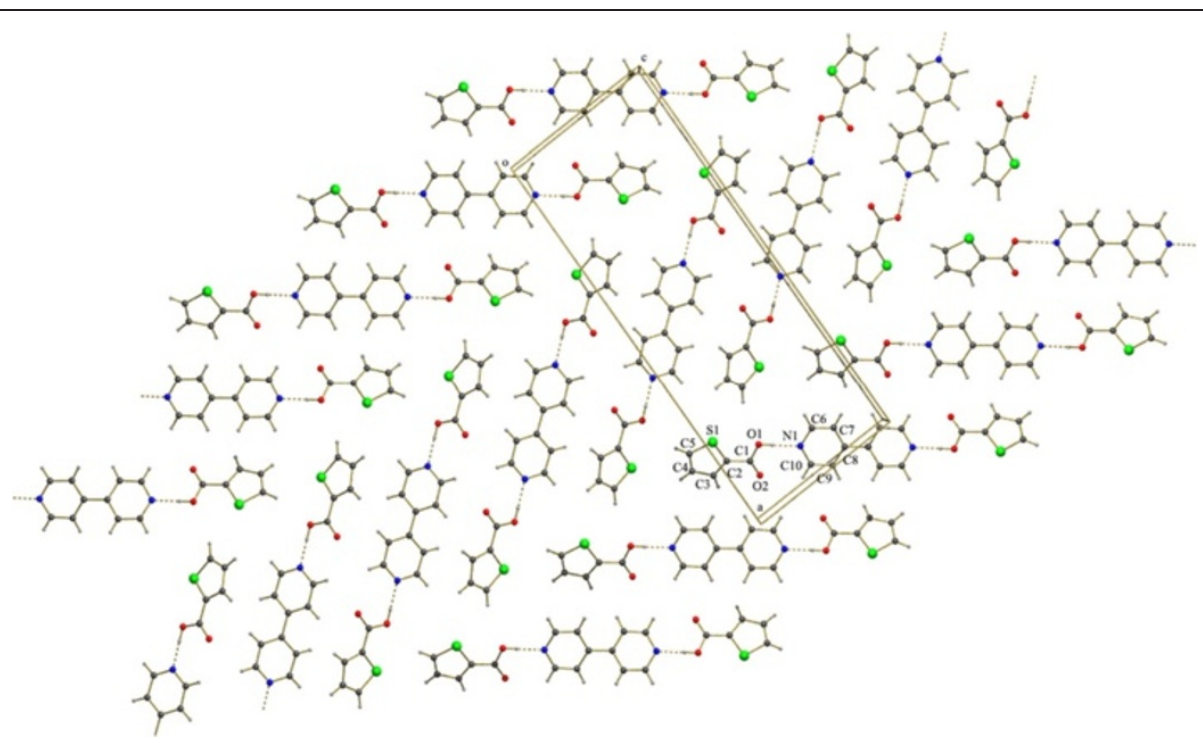

Figure 11 Formation of ladder through C-H...O hydrogen bonds in (9b). 

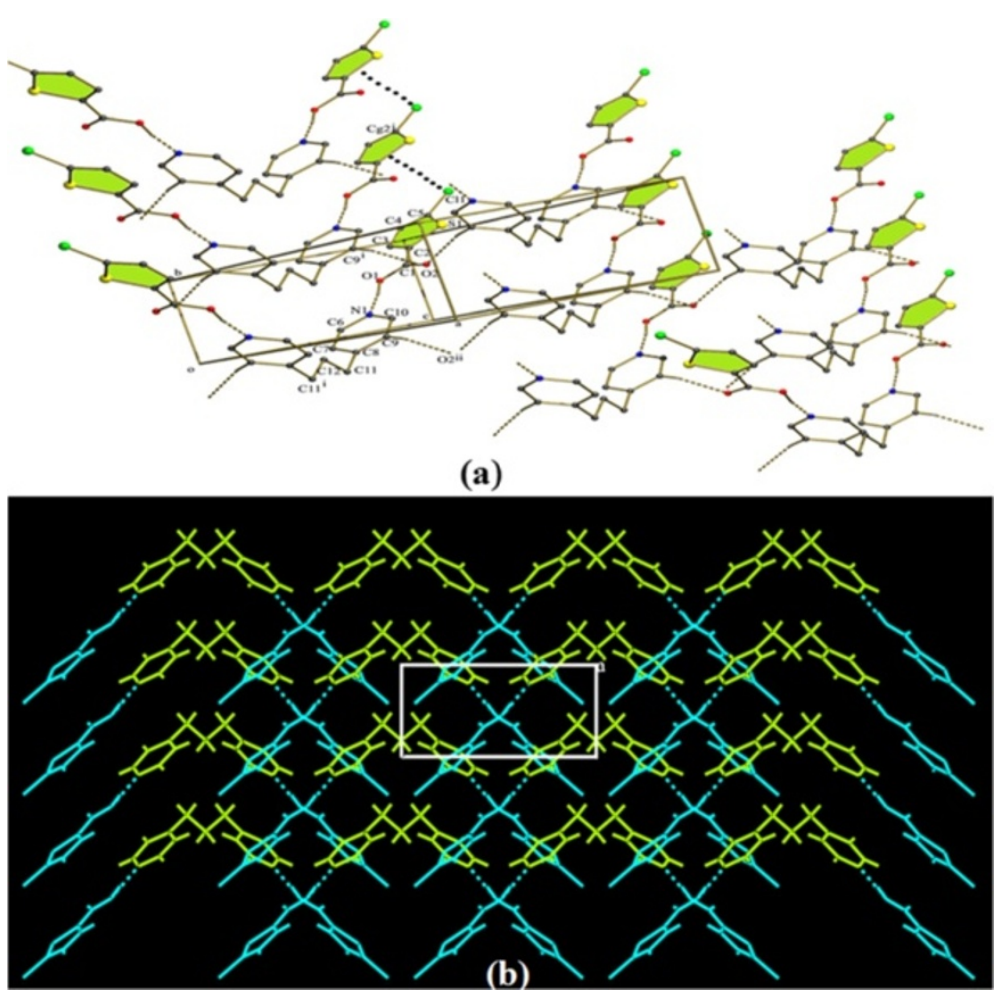

Figure 12 (a) Formation of ladders by $\mathrm{Cl} . . . \pi$ interactions. (b) Supramolecular architectures formed in (10b).

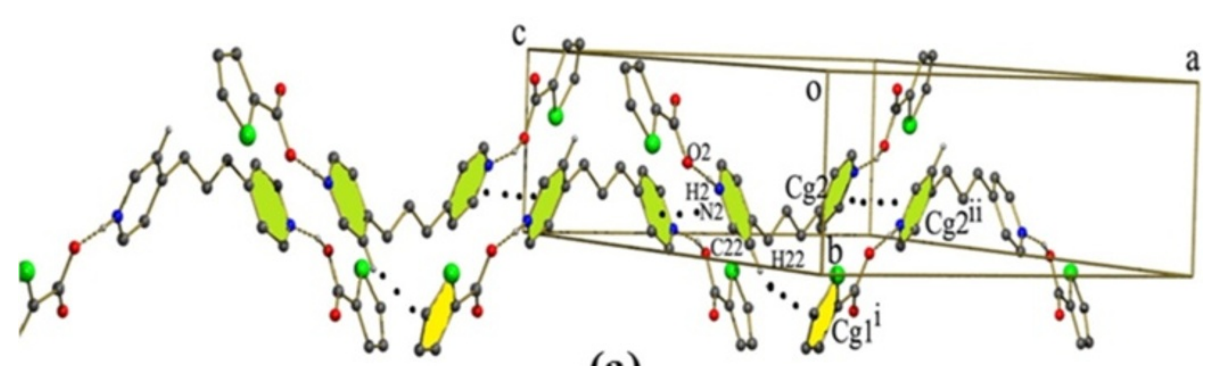

(a)

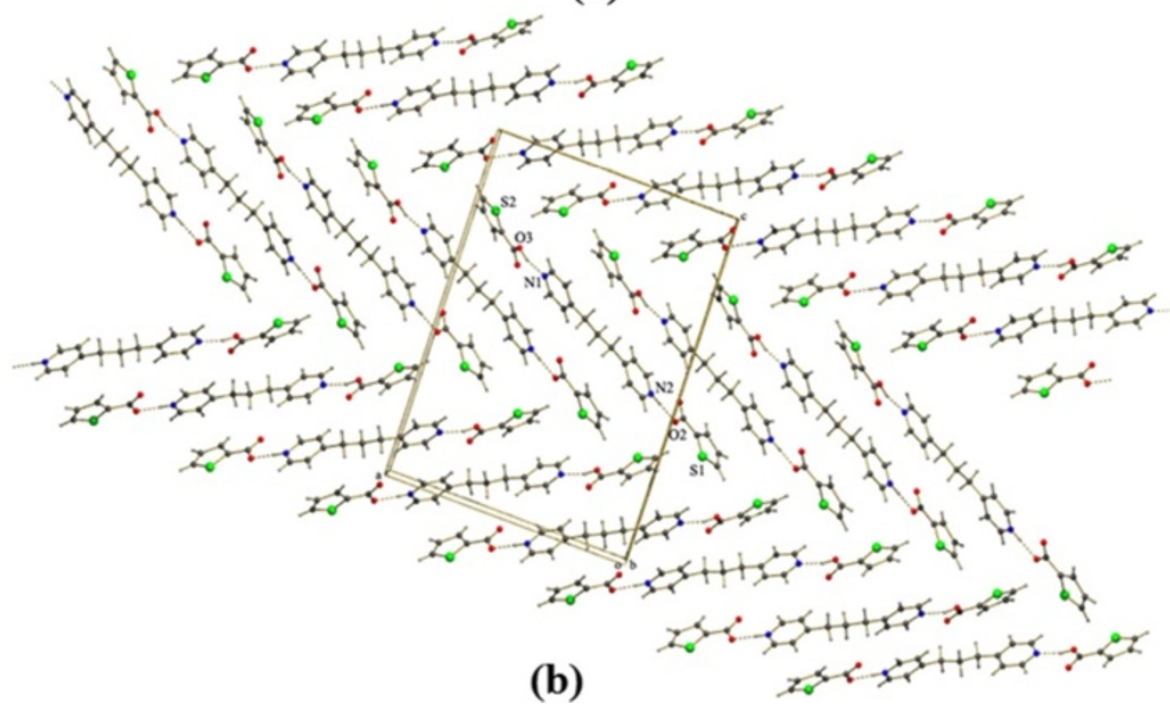

Figure 13 (a) Formation of chain by $\pi-\pi$ and C-H... interactions (b) supramolecular network in (11b). 


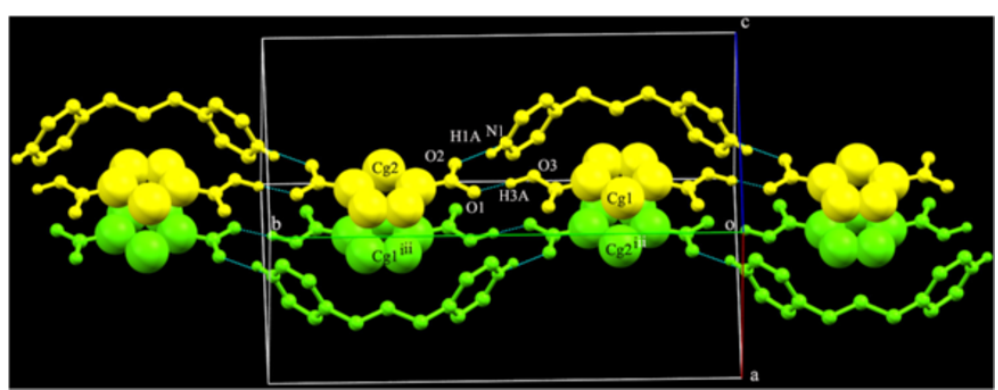

Figure 14 Formation of supramolecular chains (yellow, green) in (12b) by N-H...O and O-H...O interactions and these chains linked by stacking interactions between TDC rings (represented as spacefilled models).

\section{Crystal structure description of 5TPC44PYNO (14b)}

Similar to the preceding 44BIPY and TMBP compounds $(\mathbf{8 b}, \mathbf{9 b}$, and 10b), compound (14b) crystallizes with a $1: 2$ ratio of acid and bipyridine components. The acid group and the PYNO ring lie on the same plane, the dihedral angle between them being $4.48(16)^{\circ}$. One half of the PYNO ring connects with four other molecules (two 5-TPC molecules and two PYNO molecules) by a series of $\mathrm{C}-\mathrm{H}$... $\mathrm{O}$ and $\mathrm{O}-\mathrm{H}$... O hydrogen bonds. Thus this gives rise to two sets of $R_{2}{ }^{2}(8)$ and $R_{3}{ }^{2}(9)$ on each side of the PYNO ring (Figure 17a). Each of the $\mathrm{N}^{+}-\mathrm{O}^{-}$ functions plays a significant role by participating in bifurcated interactions to neighboring molecules; hence there is a formation of network. The network is further stabilized by a $\pi-\pi$ stacking interaction between the thiophene ring and the PYNO ring $\left(\mathrm{Cg} 1-\mathrm{Cg} 2^{\text {iv }}\right.$ where
$\mathrm{Cg} 1=\mathrm{N} 1, \mathrm{C} 6, \mathrm{C} 7, \mathrm{C} 8, \mathrm{C} 9, \mathrm{C} 10$ and $\mathrm{Cg} 2=\mathrm{S} 1, \mathrm{C} 2, \mathrm{C} 3, \mathrm{C} 4, \mathrm{C} 5$ [Symmetry code (iv) = X,1-Y,-Z] (Figure 17b).

As said earlier, carboxyl and pyridyl functional groups are known to form the most robust intermolecular interactions. The occurrence of synthons III and IV are accompanied by a strong $\mathrm{N}-\mathrm{H}$... O or $\mathrm{O}-\mathrm{H}$... $\mathrm{N}$ and weaker $\mathrm{C}-\mathrm{H}$... hydrogen bonds (Scheme $\mathbf{2 a}, \mathbf{b}$ ). This leads to the formation of $\mathrm{R}_{2}{ }^{2}$ (7) synthon. Previous reports [40] say that for the formation of this motif, strong geometrical complementarity between base and acid molecules is necessary. Our reports add value to this point, since there is a formation of a noncyclic motif of type $\mathrm{V}$ and VI in (4a, 5a, 7a-9a, 8b-13b) (Scheme 2c, d). In compounds $(\mathbf{8 b}, \mathbf{9 b}, \mathbf{1 2 b}$ and $\mathbf{1 3 b})$ the dihedral angle between the carboxylic acid group and the pyridyl group is relatively large range (Table 5 ), which may probably be

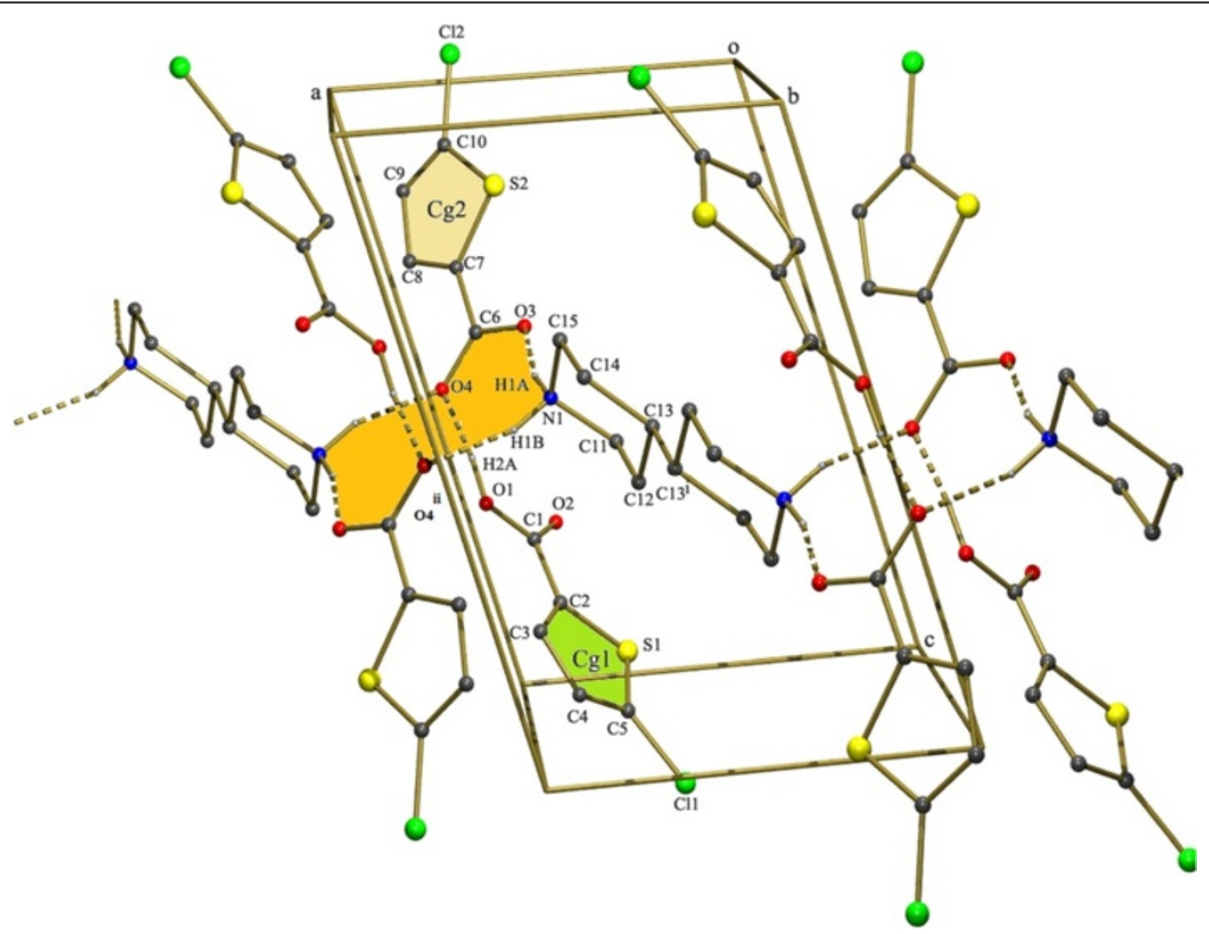

Figure $15 \mathrm{R}_{4}{ }^{4}(12)$ ring motif and bridging of the ring motifs by the bipiperazinium cations in (13b). 


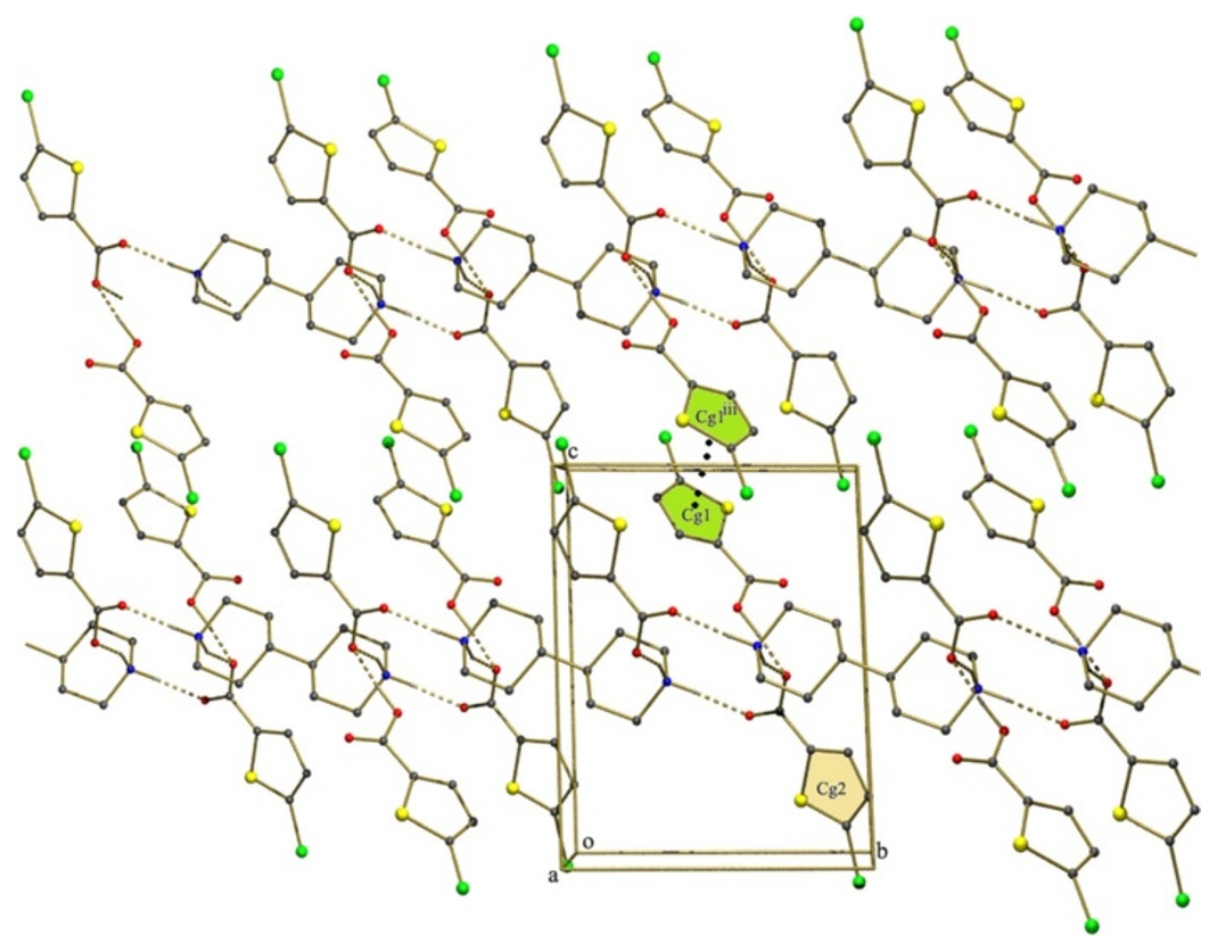

Figure 16 Two of the chains linked by $\pi-\pi$ stacking interactions between the 5-TPC rings in (13b).

the reason for the formation of non cyclic single point synthon. Also the conformational flexibility of the molecules (dihedral angles of two pyridine rings) affects the formation of this synthon which is the case in compounds (9b-12b). The value is less for 14b which also explains the reason for non formation of synthon of type V or VI (Scheme 2c, d).

Among the 14 structures reported here, 8 of them are co-crystals while the remainder are salts. Several papers have also reported and used the acid dissociation constant $\mathrm{pK}_{\mathrm{a}}$ in predicting the formation of salts/cocrystals [41]. In our recent report involving pyrimidine with various other acids we have tried to rationalize the formation of salt/cocrystals in terms of $\mathrm{pK}_{\mathrm{a}}$ values. Also in our previous report we presented a plot of $\Delta \mathrm{pKa}$ vs $\Delta \mathrm{Dc}$-o, where the $\mathrm{X}$-axis corresponding to the $\Delta \mathrm{pKa}$ and $\mathrm{Y}$-axis corresponding to $\Delta \mathrm{D}_{\mathrm{C}-\mathrm{O}}$ [where $\Delta \mathrm{pKa}=\mathrm{pKa}$ (base) $-\mathrm{pKa}$ (acid), $\Delta \mathrm{D}_{\mathrm{C}-\mathrm{O}}=$ difference between the lengths of the two $\mathrm{C}-\mathrm{O}$ bonds in a carboxyl group]. Now we present a same kind of plot using the calculated $\Delta \mathrm{pKa}$ [42] of the molecular compounds (1a-4a, 8b-12b) and measured $\Delta \mathrm{D}_{\mathrm{C}-\mathrm{O}}$ thiophene carboxylic acids used here (Figure 18). The $\mathrm{C}-\mathrm{N}-\mathrm{C}$ bond angle in AMPY and CYT, which involves acid-base interaction, ranges from 116 to $118^{\circ}$ in most cases (indicative of co-crystal formation) and increases to a higher range of $119-124^{\circ}$ indicating the formation of salts (Table 5). The scattergram indicates the densely populated boxes on the upper side which corresponds to co-crystals having larger $\Delta \mathrm{D}_{\mathrm{C}-\mathrm{O}}$ and the scarcely populated blocks on the bottom side which corresponds to formation of salts. Also from the plot it can be seen that each of the populated areas corresponds to each type of base involved in salt/cocrystal formation.

\section{Experimental}

Materials and methods

Commercial starting materials were used without further purification. 2-amino-4,6-dimethylpyrimidine, TPC, TDC, ACR,TMBP, 44BIPY, were purchased from SigmaAldrich, 5-Chloro thiophene 2- carboxylic acid (Hoechst Aktiengesellschaft), methanol/ethanol (Qualigens, India) were used (Scheme 3). IR spectra of the compounds in region $400-4000 \mathrm{~cm}^{-1}$ were recorded as pressed disks ( $1 \%$ by weight in $\mathrm{KBr}$ ) on a Shimadzu FT IR spectrophotometer.

\section{Preparation of compounds (1a-7a,8b-14b)}

Compounds (1a-3a) were prepared by mixing hot methanolic solution of AMPY with hot methanolic solution of 5-TPC/TPC/TDC in 1:1 molar ratio and were allowed to warm over a water bath for half an hour. The mixtures were cooled slowly and kept at room temperature. After a few days, colorless prismatic crystals of (1a-3a) separated out of the mother liquor. Compounds $(\mathbf{4 a}-7 \mathbf{a})$ were prepared by mixing hot methanolic solution of $5 \mathrm{TPC}$ with hot methanolic solution of CYT/BA/2NPY/ ACR in 1:1 molar ratio and were allowed to warm over 

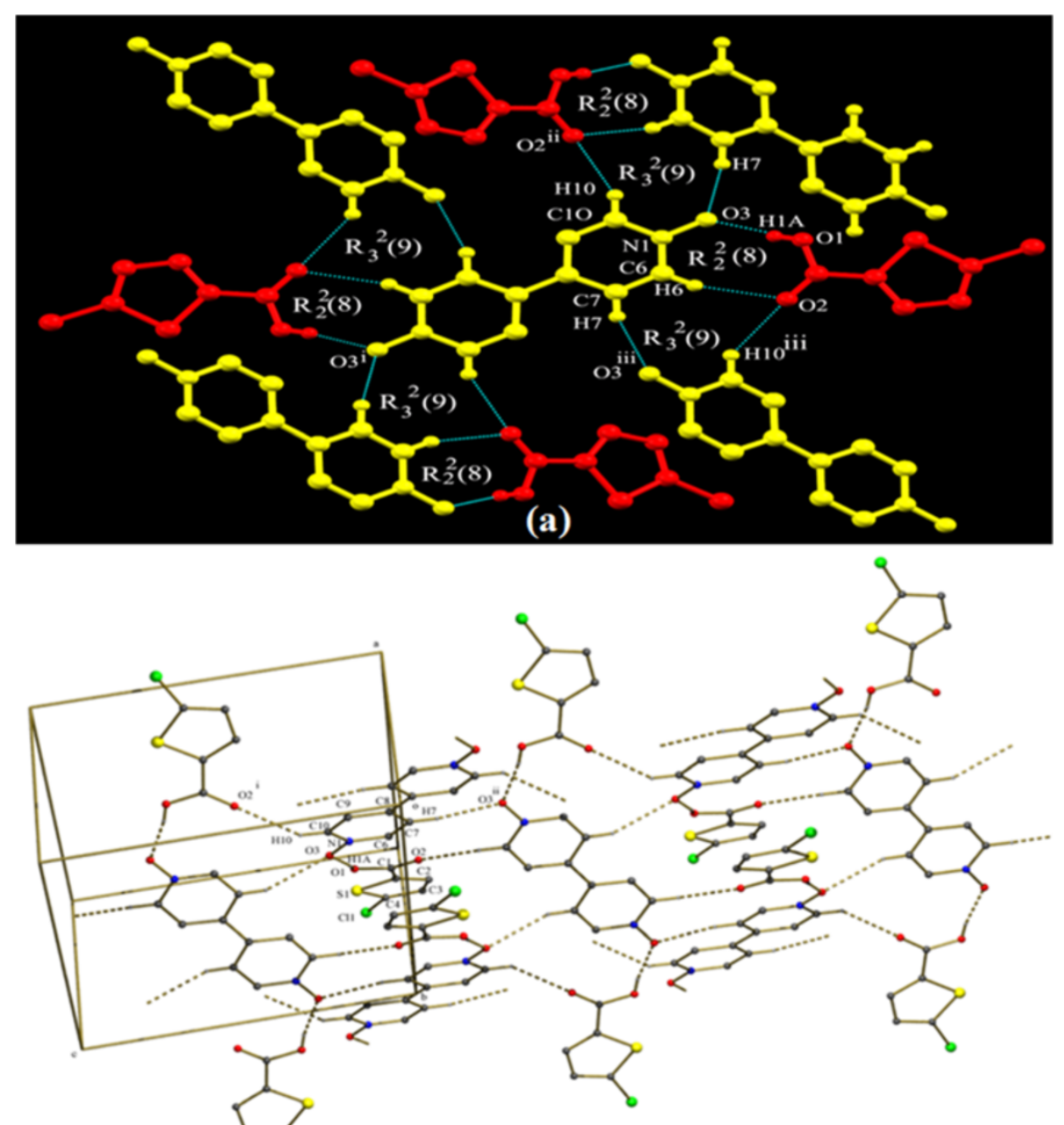

(b)

Figure 17 (a) A portion of the crystal packing of $14 b$ showing hydrogen-bonding patterns with graph-set notations $R_{3}{ }^{2}(9), R_{2}{ }^{2}(8)$. Dotted lines denote hydrogen bonds. $\mathrm{H}$ atoms non-involved in hydrogen-bonding omitted for clarity. (b) Hydrogen bonded network formed in (14b).

a water bath for half an hour. The mixtures were cooled slowly and kept at room temperature. After a few days, colorless prismatic crystals of $(\mathbf{4 a}, \mathbf{5 a})$, yellow prismatic crystals of (6a) and yellow plate like crystals of (7a) separated out of the mother liquor. IR selected bands for $(1 \mathrm{a})\left(\mathrm{cm}^{-1}\right)$ : 3346(s), 3174(m), 2924(m), 2852(m), 2378(m), 1660(s), 1589(s), 1531(s), 1421(s), 1330(s), 1274(s), 1101(s), 1060(s), 993(s), 815(s), 756(s), 574(s), 518(s), 466(s). IR selected bands for $(2 \mathrm{a})\left(\mathrm{cm}^{-1}\right)$ : 3334(m), 3169(m), 3074(m), 1672(s), 1604(s), 1517(s), 1417(s), 1375(s), 1321(s), 1107(s), 1029(s), 964(s), 860(s), 823(s), 771(s), 738(s), 597(m). IR selected bands for (3a) $\left(\mathrm{cm}^{-1}\right)$ : 3344(s), 2924(m), 2374(s), 1658(s), 1597(s), 1527(s), 1438(s), 1350(s), 1276(s), 1024(s), 833(s), 756(s), 667(s), 576(s). IR selected bands for $(4 \mathrm{a})\left(\mathrm{cm}^{-1}\right)$ : 3375(m), 3101(m), 1683(s), 1658(s), 1531(s), 1433(s), 1332(s), 1278(s), 1236(s), 1105(s), 1004(s), 812(s), 752(s), 669(s), 493(s). IR selected bands for (5a) $\left(\mathrm{cm}^{-1}\right)$ : 3282(s), 1627(s), 1415(s), 1330(s), 1290(s), 1138(s),1103(s), 997(s), 752(s), 638(s), 526(s). IR selected bands for $(\mathbf{6 a})\left(\mathrm{cm}^{-1}\right)$ : 3259(s), 3003(m), 2526(m), 1674(s), 1531(s), 1487(s), 1431(s), 1365(s), 1253(s), 1157(s), 1051(s), 977(s), 792(s), 761(s), 621(s), 514(s). IR selected bands for (7a) $\left(\mathrm{cm}^{-1}\right)$ : 3402(m), 1685(s), 1427(s), 1327(s), 923(s),736(s), 601(s), 445(s).

Similarly compounds $(\mathbf{8 b}, \mathbf{9 b})$ were prepared by mixing hot ethanolic solution of 44BIPY with hot ethanolic solution of $5 \mathrm{TPC} / \mathrm{TPC}$ in $1: 1$ molar ratio and were allowed to warm over a water bath for half an hour. The mixtures were cooled slowly and kept at room temperature. After a few days, colorless needle typed crystals of $(\mathbf{8 b}, \mathbf{9 b})$ separated out of the mother liquor. IR selected bands for $(\mathbf{8 b})\left(\mathrm{cm}^{-1}\right)$ : 3425(m), 2924(s), 2374(s), 
Table 5 Comparisons of dihedral angles (between carboxylic acid and pyridine) and C-N-C bond angles (involved in acid-base interaction) in compounds 1a-14b

\begin{tabular}{|c|c|c|c|c|c|c|}
\hline Compound & Acid & Base & Synthon & $\begin{array}{l}\text { Dihedral angle between } \\
\text { carboxylic acid and pyridine }\end{array}$ & $\begin{array}{l}\text { Dihedral angle between } \\
\text { two pyridine rings }\end{array}$ & $\begin{array}{c}\text { Acid-base interaction } \\
\text { involved } \mathrm{C}-\mathrm{N}-\mathrm{C} \text { bond angle }\end{array}$ \\
\hline \multirow{2}{*}{1.} & \multirow{2}{*}{ 5TPC } & \multirow{2}{*}{ AMPY } & \multirow{2}{*}{ HT } & \multirow{2}{*}{$14.2(15), 9.4(5)$} & & 116.89 \\
\hline & & & & & & 117.69 \\
\hline \multirow{2}{*}{2.} & \multirow{2}{*}{ TPC } & \multirow{2}{*}{ AMPY } & \multirow{2}{*}{ LHT } & \multirow{2}{*}{$19.1(4)$} & & 118.80 \\
\hline & & & & & & 117.30 \\
\hline \multirow{4}{*}{3.} & \multirow{4}{*}{ TDC } & \multirow{4}{*}{ AMPY } & \multirow{4}{*}{ HT } & \multirow{4}{*}{$1.8(13), 2.4(12)$} & & 117.76 \\
\hline & & & & & & 117.76 \\
\hline & & & & & & 117.92 \\
\hline & & & & & & 118.45 \\
\hline \multirow{4}{*}{4.} & \multirow{4}{*}{ 5TPC } & \multirow{4}{*}{$2 N P Y$} & \multirow{4}{*}{$\mathrm{HD}$} & \multirow{4}{*}{$8.5(3)$} & & 122.01 \\
\hline & & & & & & 123.94 \\
\hline & & & & & & 121.43 \\
\hline & & & & & & 119.49 \\
\hline 5. & 5TPC & CYT & $\mathrm{HD}$ & $57.0(2)$ & & 103.18 \\
\hline 6. & 5TPC & $\mathrm{BA}$ & $\mathrm{HD}$ & $13(3)$ & & 117.84 \\
\hline 7. & 5TPC & $A C R$ & $\mathrm{HD}$ & $63.6(8)$ & & 120.06 \\
\hline 8. & 5TPC & 44BIPY & $\mathrm{HD}$ & $29.68(10)$ & $0.00(7)$ & 117.23 \\
\hline 9. & TPC & 44BIPY & $\mathrm{HD}$ & $15.6(3)$ & $35.13(12)$ & 117.58 \\
\hline 10. & 5TPC & 44TMBP & $\mathrm{HD}$ & $7.5(16)$ & $78.31(14)$ & 116.38 \\
\hline \multirow{2}{*}{11.} & \multirow{2}{*}{ TPC } & \multirow{2}{*}{ 44TMBP } & \multirow{2}{*}{ HT } & \multirow{2}{*}{$2.9(4), 7.9(4)$} & \multirow{2}{*}{$51.7(4)$} & 117.25 \\
\hline & & & & & & 117.85 \\
\hline 12. & TDC & 44TMBP & $\mathrm{HD}$ & $69.16(1)$ & 82.15 & 121.82 \\
\hline 13. & 5TPC & 44BIPZ & $\mathrm{HD}$ & $59.06(3)$ & $0.00(1)$ & 111.32 \\
\hline 14. & 5TPC & 44PYNO & $\mathrm{HD}$ & $5.34(3)$ & $0.00(1)$ & 119.93 \\
\hline
\end{tabular}

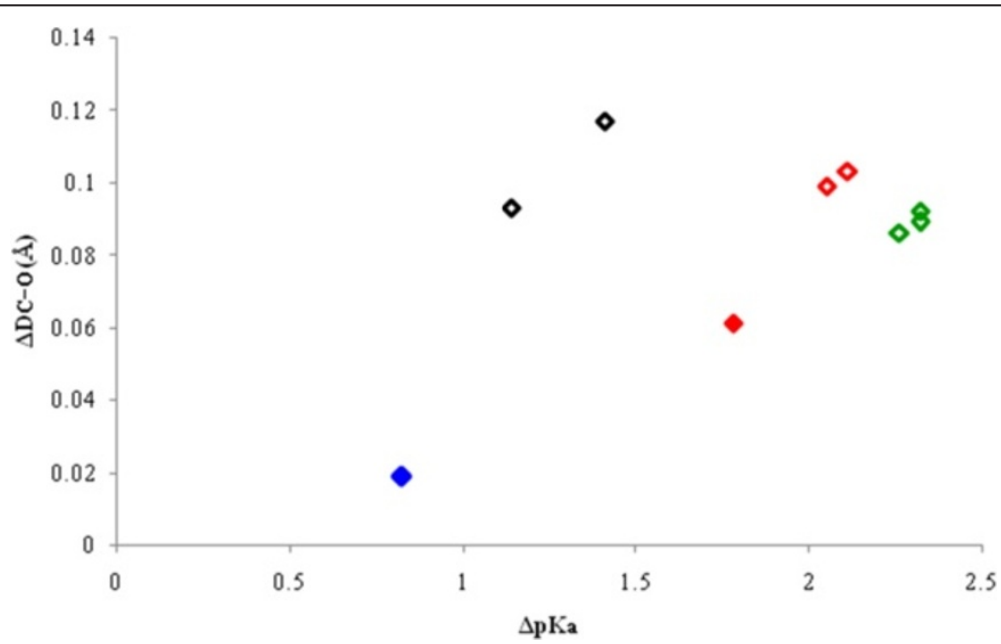

Figure 18 Plot of $\Delta$ pKa vs $\Delta$ Dc-o for compounds. Blue (cytosine salt) red block (ampy salt) red box (ampy cocrystal) black (bipy cocrystal) green (44TMBP cocrystal). 
1654(s), 1595(s), 1421(s), 1325(s), 1265(s), 999(s), 806(s), 744(s), 624(s), 462(s). IR selected bands for (9b) $\left(\mathrm{cm}^{-1}\right): 3107(\mathrm{~m}), 1691(\mathrm{~s}), 1600(\mathrm{~s}), 1525(\mathrm{~m}), 1406(\mathrm{~s}), 1357(\mathrm{~s})$, 1274(s), 1056(s), 1006(s), 813(s), 756(s), 717(s), 626(s), 459(s).

Compounds (10b-12b) were prepared in same procedure where hot ethanolic solution of TMBP was mixed with hot ethanolic solution of 5TPC/TPC/TDC in 1:1 molar ratio. After a few days, colorless plate type crystals of (10b-12ba) separated out of the mother liquor. Similarly $(\mathbf{1 3 b}, \mathbf{1 4 b})$ were prepared by mixing hot ethanolic solution of 5-TPC with hot ethanolic solution of 44BIPZ/44PYNO in 1:1 molar ratio and were allowed to warm over a water bath for half an hour. The mixtures were cooled slowly and kept at room temperature. After a few days, colorless needle type crystals of (13b) and pale yellow prismatic crystals of (14b) separated out of the mother liquor. IR selected bands for $(\mathbf{1 0 b})\left(\mathrm{cm}^{-1}\right)$ : 3427(m), 1612(s), 1429(s), 1026(s), 810(s), 987(s), 810(s), 758(s), 518(s), 460(s). IR selected bands for (11b) $\left(\mathrm{cm}^{-1}\right): 3448(\mathrm{~m}), 1681(\mathrm{~s}), 1614(\mathrm{~s})$, 1523(s), 1415(s), 1357(s), 1286(s), 1215(s), 1031(s), 821(s), 759(s), 640(s), 501(s), 455(s). IR selected bands for (12b) $\left(\mathrm{cm}^{-1}\right)$ : 3452(m), 1683(s), 1658(s), 1521(s), 1419(s), 1207(s), 1105(s), 1056(s), 815(s), 750(s), 580(s), 509(s). IR selected bands for (13b) $\left(\mathrm{cm}^{-1}\right)$ : 2960(s), 2490(s), 1687(s), 1589(s), 1533(s), 1436(s), 1332(s), 1278(s), 1107(s), 1006(s), 921(s), 813(s), 748(s), 669(s), 528(s), 491(s). IR selected bands for (14b) $\left(\mathrm{cm}^{-1}\right):$ 3423(m), 3076(s), 2405(s), 1687(s), 1535(s), 1477(s), 1411(s), 1330(s), 1271(s), 1213(s), 1184(s), 1026(s), 995(s), 947(s), 810(s), 748(s), 551(s), 466(s).

\section{Crystal structure determination}

Intensity data sets were collected at room temperature, on a BRUKER SMART APEXII CCD [43] area-detector diffractometer equipped with graphite monochromated Mo $K \alpha$ radiation $(\lambda=0.71073 \AA)$. The data were reduced by using the program SAINT [43] and empirical absorption corrections were done by using the SADABS [43]. The structures were solved by direct methods using SHELXS-97 [44] and subsequent Fourier analyses, refined anisotropically by full-matrix least-squares method using SHELXL-97 [44] within the WINGX suite of software, based on $\mathrm{F}^{2}$ with all reflections. All carbon hydrogens were positioned geometrically and refined by a riding model with $\mathrm{U}_{\text {iso }} 1.2$ (1.5 for methyl groups) times that of attached atoms. All non $\mathrm{H}$ atoms were refined anisotropically. The molecular structures were drawn using the ORTEP-III [45], POV-ray [46] and MERCURY [47]. The crystals remained stable throughout the data collection. The dihedral angles were determined using PLATON using the experimental results reported here. The differences in theta values with that of expected values for compounds $8 \mathrm{~b}$ and $11 \mathrm{~b}$ are due to the poor quality of crystals.

\section{Conclusions}

Structural studies of these 14 supramolecular compounds of N-heterocyclic bases and various thiophene carboxylic acids show differences depending on the number of proton acceptors (nitrogen atoms) in the base molecule. Of the 14 compounds carboxylic acid to pyrimidine/pyridine proton transfer has occurred in five of these compounds. The (HT) and (LHT) are dominant in the crystal structures of the adducts containing N-heterocyclic bases with two proton acceptors (1a-7a) in the heterocyclic ring and thiophene carboxylic acids. N-heterocyclic bases with one proton acceptor in the heteroyclic ring (8b-14b) form a linear one point hetero synthon (HD) with thiophene carboxylic acids. Also in presence of the classical complementary pair of $\mathrm{O}-\mathrm{H} \cdots \mathrm{N} / \mathrm{O}^{-} \cdots \mathrm{H}-\mathrm{N}^{+}$and $\mathrm{N}-\mathrm{H} \cdots \mathrm{O}^{-} / \mathrm{N}-\mathrm{H} \cdots \mathrm{O}$ hydrogen bonds the non classical interactions like $\mathrm{Cl} \ldots \pi, \mathrm{C}-\mathrm{H} . . \mathrm{Cl}, \mathrm{C}-\mathrm{O} . . \mathrm{Cl}, \mathrm{C}-\mathrm{H} . . . \mathrm{S}$, $\mathrm{Cl}$...Cl and $\mathrm{C}-\mathrm{H}$... $\pi$ take part in determining the supramolecular architectures. The majority of the compounds showed $\pi-\pi$ stacking between the pyrimidine-pyrimidine, pyridine-pyridine and acid-acid moieties rather than acid-pyridine or acid-pyrimidine moieties. The compounds involving bipyridine and bipyridine type ligands mostly show the three molecules aggregate made up of bipyridine/bipyridine type ligands bridging the two carboxylic acids. The above results and the synthetic strategies can also be employed practically to other biologically relevant systems.

\section{Supplementary material}

CCDC 973226-973239 contain the supplementary crystallographic data for the complexes [1a-7a], [8b-14b] respectively and can be obtained free of charge via http://www.ccdc.cam.ac.uk/conts/retrieving.html, or from the Cambridge Crystallographic Data Center, 12 Union Road, Cambridge CB2 IEZ, UK; fax:(+44)1223-336-033; or e-mail: deposit@ccdc.cam.ac.uk.

\section{Competing interests}

The authors declare that they have no competing interests.

\section{Authors' contributions}

This work was prepared in the research group of PTM. He proposed the work and drafted the manuscript. SJJ participated in the design and presided over the experiments, collected the X-ray data and drafted the manuscript. Both authors read and approved the final manuscript.

\section{Acknowledgements}

SJJ thank the UGC-SAP for the award of RFSMS. The authors thank the DST India (FIST programme) for the use of the NMR and diffractometer at the School of Chemistry, Bharathidasan University, Tiruchirappalli, Tamilnadu, India.

Received: 29 November 2013 Accepted: 12 March 2014 Published: 22 March 2014

\section{References}

1. Desiraju GR, Steiner T: The Weak Hydrogen Bond: In Structural Chemistry and Biology. Vol. 9. New York: Oxford University Press; 2001. 
2. Jeffrey GA: An Introduction to Hydrogen Bonding, Volume 12. New York: Oxford University Press; 1997

3. Desiraju GR: Supramolecular synthons in crystal engineering-a new organic synthesis. Angew Chem Int Ed Engl 1995, 34:2311-2327.

4. Schmidt GMJ: Photodimerization in the solid state. Pure Appl Chem 1971, 27:126.

5. Almarsson O, Zaworotko MJ: Crystal engineering of the composition of pharmaceutical phases. Do pharmaceutical co-crystals represent a new path to improved medicines? Chem Commun 2004, 17:1889-1896.

6. Sander JRG, Bucar DK, Henry RF, Giangiorgi BN, Zhang GGZ, MacGillivray LR: 'Masked synthons' in crystal engineering: insulated components in acetaminophen cocrystal hydrates. CrystEngComm 2013, 15:4816-4822.

7. Ebenezer S, Muthiah PT: Supramolecular architectures in the co-crystals involving carboxylic acids and 1, 2-bis (4-pyridyl) ethane, an extended bipyridyl type ligand. J Mol Struct 2011, 990:281-289.

8. Ebenezer S, Muthiah PT, Butcher RJ: Design of a series of isostructural Co-crystals with aminopyrimidines: isostructurality through chloro/methyl exchange and studies on supramolecular architectures. Cryst Growth Des 2011, 11:3579-3592.

9. Ebenezer S, Muthiah PT: Design of Co-crystals/salts of aminopyrimidines and carboxylic acids through recurrently occurring synthons. Cryst Growth Des 2012, 12:3766-3785.

10. Lieblein AL, Krämer M, Dreuw A, Fürtig B, Schwalbe H: Bonds in DNA i-motifs the nature of hydrogen bonds in cytidine...H + ...cytidine DNA base pairs. Angew Chem Int Ed Engl 2012, 51:4067-4070.

11. Szatyłowicz H, Sadlej-Sosnowska N: Characterizing the strength of individual hydrogen bonds in DNA base pairs. J Chem Inf Model 2010, 50:2151-2161.

12. Gushchin PV, Kuznetsov ML, Haukka M, Kukushkin VY: Recognition of a novel type $\mathrm{X}=\mathrm{N}-\mathrm{Hal} \cdots \mathrm{Hal}(\mathrm{X}=\mathrm{C}, \mathrm{S}, \mathrm{P}$; $\mathrm{Hal}=\mathrm{F}, \mathrm{Cl}, \mathrm{Br}$, I) halogen bonding. J Phys Chem A 2013, 117:2827-2834.

13. Andrews $M B$, Cahill CL: Metal-organic hybrids involving the $\left[\mathrm{UO}_{2} \mathrm{Cl}_{3}\left(\mathrm{NO}_{3}\right)\right]^{2-}$ tecton and the role of halogen polarizability. CrystEngComm 2013, 15:3082-3086.

14. Ji B, Zhang $Y$, Deng $D$, Wang W: Improper halogen bond in the crystal structure. CrystEngComm 2013, 15:3093-3096

15. Shan N, Zaworotko MJ: The role of cocrystals in pharmaceutical science. Drug Discov Today 2008, 13:440-446.

16. Luo YH, Sun BW: Pharmaceutical Co-crystals of pyrazinecarboxamide (PZA) with various carboxylic acids: crystallography, hirshfeld surfaces, and dissolution study. Cryst Growth Des 2013, 13:2098-2106.

17. Mora AJ, Belandria LM, Ávila EE, Seijas LE, Delgado GE, Miró A, Almeida R, Brunelli M, Fitch AN: Investigating the stability of double head to tail dimers and ribbons in multicomponent crystals of cis-4-aminocyclohexane carboxylic acid with water and oxalic acid. Cryst Growth Des 2013, 13:1849-1860.

18. Goswami PK, Thaimattam R, Ramanan A: Multiple crystal forms of p-Aminosalicylic acid: salts, salt Co-crystal hydrate, Co-crystals, and Co-crystal polymorphs. Cryst Growth Des 2012, 13:360-366.

19. Balasubramani K, Muthiah PT, Lynch DE: 2-Amino-4, 6-dimethylpyrimidine4-hydroxybenzoic acid (1/1). Acta Crystalogr E 2006, 62:02907-02909.

20. Subashini A, Muthiah PT, Lynch DE: 2-Amino-4, 6-dimethylpyrimidinium 3, 5-dinitrobenzoate dihydrate. Acta Crystalogr E 2008, 64:0426-0426.

21. Thanigaimani K, Muthiah PT, Lynch DE: Hydrogen-bonded supramolecular motifs in 2-amino-4, 6-dimethoxypyrimidinium 4-hydroxybenzoate monohydrate, 2-amino-4, 6-dimethoxypyrimidinium 6-carboxypyridine2-carboxylate monohydrate and 2-amino-4, 6-dimethoxypyrimidinium hydrogen (2R, 3R)-tartrate 2-amino-4, 6-dimethoxypyrimidine. Acta Crystalogr C 2007, 63:0295-0300.

22. Ebenezer S, Muthiah PT: 4, 6-Dimethoxypyrimidin-2-amine-2-(1H-indol-3-yl) acetic acid (1/1). Acta Crystalogr E 2010, 66:02634-02635.

23. Jenniefer SJ, Muthiah PT: Supramolecular architectures of two novel organic-inorganic hybrid materials containing identical monomeric uranyl units. Acta Crystalogr C 2011, 67:m69-m72.

24. Balasubramani K, Muthiah PT, Lynch D: $R_{2}^{2}(8)$ motifs in Aminopyrimidine sulfonate/carboxylate interactions: Crystal structures of pyrimethaminium benzenesulfonate monohydrate (2: 2: 1) and 2-amino-4, 6-dimethylpyrimidinium sulfosalicylate dihydrate (4: 2: 2). Chem Cen J 2007, 1:28.

25. Thanigaimani K, Muthiah PT, Lynch DE: Hydrogen-bonding patterns in 2-amino-4, 6-dimethoxypyrimidinium salicylate. Acta Crystalogr E 2007, 63:04555-04556
26. Baskar Raj S, Sethuraman V, Francis S, Hemamalini M, Muthiah PT, Bocelli G, Cantoni A, Rychlewska U, Warzajtis B: Supramolecular organisation via hydrogen bonding in trimethoprim sulfonate salts. CrystEngComm 2003, 5:70-76.

27. Jenniefer SJ, Muthiah PT: Synthesis, characterization and X-ray structural studies of four copper (II) complexes containing dinuclear paddle wheel structures. Chem Cen J 2013, 7:1-15.

28. Jenniefer SJ, Muthiah PT, Priyadharshni R: Syntheses, characterization, and supramolecular architectures of two lead (II) complexes of 8-quinolinol. J Coord Chem 2012, 65:4397-4408.

29. Jenniefer SJ, Muthiah PT: Supramolecular architectures and structural diversity in a series of lead (II) Chelates involving 5-Chloro/Bromo thiophene-2-carboxylate and N, N'-donor ligands. Chem Cen J 2013, 7:139.

30. Jenniefer SJ, Muthiah PT, Muthukumaran G: Solvent dependent supramolecular interactions in two 5-chloro thiophene 2-carboxylate bridged dinuclear copper (II) complexes. Inorg Chim Acta 2013, 406:100-105.

31. Qin JL: 4,4'-Bipyridine-5-fluoroisophthalic acid .(1/1). Acta Crystalogr E 2011, 67:0589

32. Bowers JR, Hopkins GW, Yap GPA, Wheeler KA: Structural consequences of strong and weak interactions to binary benzoic acid/bipyridine supramolecular assemblies. Cryst Growth Des 2005, 5:727-736.

33. García-Terán JP, Castillo O, Luque O, García-Couceiro U, Beobide G, Román P: Molecular recognition of protonated cytosine ribbons by metal-oxalato frameworks. Cryst Growth Des 2007, 7:2594-2600.

34. Benali-Cherif N, Falek W, Direm A: Cytosinium-hydrogen maleate-cytosine (1/1/1). Acta Crystalogr E 2009, 65:03058-03059.

35. Kruger T, Bruhn C, Steinborn D: Synthesis of [(MeCyt) $2 \mathrm{H}] \mathrm{I}$-structure and stability of a dimeric threefold hydrogen-bonded 1-methylcytosinium 1-methylcytosine cation. Org Biomol Chem 2004, 2:2513-2516.

36. Sridhar B, Ravikumar K: Supramolecular hydrogen-bonded networks in cytosinium succinate and cytosinium 4-nitrobenzoate cytosine monohydrate. Acta Crystalogr C 2008, 64:0566-0569.

37. Byre M, Cox P, Kay G, Nixon E: Supramolecular structures of six adeninecarboxylic acid complexes. Crystallorg Eng Comm 2009, 11:135-142.

38. Lippert B, Gupta D: Promotion of rare nucleobase tautomers by metal binding. Dalton Trans 2009, 24:4619-4634.

39. Tamilselvi D: Ph.D. Thesis, Bharathidasan University. 2011.

40. Orola L, Veidis MV, Mutikainen I, Sarcevica I: Neutral and ionic supramolecular complexes of phenanthridine and some common dicarboxylic acids: hydrogen bond and melting point considerations. Cryst Growth Des 2011, 11:4009-4016.

41. Sarma B, Nath NK, Bhogala BR, Nangia A: Synthon competition and cooperation in molecular salts of hydroxybenzoic acids and aminopyridines. Cryst Growth Des 2009, 9:1546-1557.

42. Hilal SH, Carreira LA, Karickhoff SW: A rigorous test for SPARC's chemical reactivity models: estimation of more than 4300 ionization pKa's. Quant Struc Act Rel 1995, 14:348-355.

43. Bruker: APEX2, SAINT and SADABS. Madison, Wisconsin, USA: Bruker AXS Inc.; 2008.

44. Sheldrick GM: A short history of SHELX. Acta Crystallorg A 2008, 64:112-122.

45. Spek AL: Structure validation in chemical crystallography. Acta Crystallorg D 2009, 65:148-155

46. Farrugia LJ: POV-Ray - 3.5. 2003. Glasgow University, United Kingdom

47. Macrae CF, Bruno IJ, Chisholm JA, Edgington PR, McCabe P, Pidcock E, Rodriguez-Monge L, Taylor R, van de Streek J, Wood PA: Mercury CSD 2.0 - new features for the visualization and investigation of crystal structures. J App/ Crystallogr 2008, 41:466-470.

doi:10.1186/1752-153X-8-20

Cite this article as: Jennifer and Muthiah: Design of co-crystals/salts of some Nitrogenous bases and some derivatives of thiophene carboxylic acids through a combination of hydrogen and halogen bonds. Chemistry Central Journal 2014 8:20. 